DOI: $10.24275 /$ uama.6746.7555

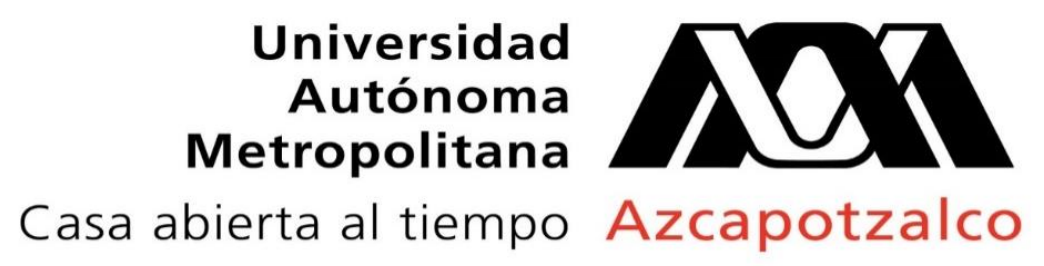

\title{
Estudio hidrodinámico de tanques agitados para la producción de recubrimiento blanco base agua
}

Que para obtener del grado de:

Maestría en Ingeniería de Procesos

Presenta:

\section{Adriana Pamela Herrera Mendoza}

Director de tesis:

Dr. Jorge Ramírez Muñoz
Co-Director de tesis:

Dr. Valaur Ekbalam Márquez Baños

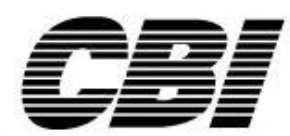

División de

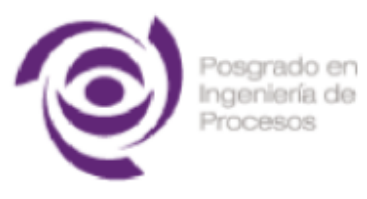




\section{AGRADECIMIENTOS}

Gracias a Dios por guiarme en cada paso que doy y por permitirme obtener un logro más en mi vida; obtener el grado de maestría. A mis padres por hacerme la persona que hoy soy, por acompañarme e impulsarme en mis momentos de dudas durante esta etapa. A mis hermanos por acompañarme en mis desvelos y por haberme facilitado con sus consejos esta etapa.

Agradezco a la Universidad Autónoma Metropolitana y a Axalta Coating Systems por haberme brindado la oportunidad de estudiar la maestría y todo lo necesario para que la pudiera realizar, especialmente a Jorge Hirata y a Mariano Rodríguez.

Doy un reconocimiento de total gratitud a mi asesor el Dr. Jorge Ramírez Muñoz por todo el apoyo y orientación brindada durante el desarrollo de este proyecto, también por su gran ejemplo de constancia y disciplina.

Agradezco a mi co-asesor y amigo Valaur Ekbalam Márquez Baños por el tiempo, la paciencia, los consejos, la amistad y sobre todo la confianza que me brindó durante el desarrollo de este proyecto.

También agradezco a los que hoy considero amigos: Aarón, Adrián y Román que con sus consejos y aportaciones logré culminar este proyecto de la mejor manera. También a mis compañeros de generación: Cesar, Edgar, Erika, Laura, Oscar y Yunnuen.

Agradezco infinitamente a Jessica, Karen, Lalo y Oscar por hacer mucho más especial cada momento importante de mi vida con su presencia. 


\section{RESUMEN}

En el presente trabajo se realizó un proyecto de vinculación universidad-industria en el que se compara el desempeño hidrodinámico de tres impulsores existentes en tanques agitados en una planta de manufactura de pinturas de la empresa Axalta Coating Systems. Estos son, impulsor de cuatro paletas inclinadas a $45^{\circ}$ (PBT4), impulsor de seis paletas inclinadas a $35^{\circ}$ (PBT6), e impulsor de alta eficiencia de tres paletas inclinadas y puntas curveadas tipo Chemineer (HE3). Para ello se utilizó Dinámica de Fluidos Computacional y mediciones experimentales de consumo de potencia. El estudio se realizó en un tanque cilíndrico de 4 litros operando en régimen turbulento (número de Reynolds mayor a 14,000) usando dos tipos de fluidos; agua y recubrimiento blanco fluidos newtonianos y adelgazantes. En todas las simulaciones y validaciones experimentales se mantuvo la similitud geométrica con las condiciones existentes en planta.

Se realizó un análisis de independencia de malla, comparando mallas con un incremento del doble de números de elementos, en la cual se eligió la de menor variabilidad de las propiedades hidrodinámicas respecto a la anterior. Una vez obtenida la malla independiente se obtuvieron los campos de velocidad, la dependencia de los números de potencia $\left(\mathrm{N}_{\mathrm{P}}\right)$ y de bombeo $\left(\mathrm{N}_{\mathrm{Q}}\right)$ de cada uno de los impulsores en estudio a diferentes condiciones de operación similares a las existentes en planta.

Se encontró que en régimen turbulento tanto para el fluido newtoniano como el no newtoniano, el número de potencia es mayor para el impulsor PBT4 y el menor para el PBT6. Para ambos fluidos, el número de bombeo fue mayor para el impulsor PBT4 y el menor se obtuvo para el PBT6. La relación de efectividad de mezclado $\left(\mathrm{N}_{\mathrm{Q}} / \mathrm{N}_{\mathrm{P}}\right)$ que se encontró es que el impulsor HE3 de Chemineer tiene el mayor valor para el fluido newtoniano, mientras que para el fluido no newtoniano, los valores son muy similares para los impulsores PBT4 y HE3.

Para el caso de estudio específico de este trabajo se concluyó que para la homogeneización de un recubrimiento blanco manufacturado en la empresa Axalta Coating Systems utilizando los impulsores PBT4 y HE3 tendrían un desempeño muy similar, mientras que el impulsor PBT6 tendría el peor desempeño. Considerando que el impulsor PBT4 es un agitador de propósito general y puede usarse en una gran cantidad de 
aplicaciones, y además, es más fácil de manufacturar y su costo es más bajo, se tendría que el agitador PBT4 exhibe un mejor desempeño que el impulsor HE3. 


\section{ABSTRACT}

In the present work, a university-industry linkage project was carried out in which the hydrodynamic performance of three existing impellers in agitated tanks in a Paint manufacturing plant of the company Axalta Coating Systems is compared. These are $45^{\circ}$ inclined four vane impeller (PBT4), $35^{\circ}$ inclined six vane impeller (PBT6), and Chemineer type curved tip three inclined vane high efficient impeller (HE3). For this, Computational Fluid Dynamics and experimental measurements of power consumption were used. The study was carried out in a 4-liter cylindrical tank operating in a turbulent regime (Reynolds numbers greater than 14,000) using two types of fluids; water and white coating like Newtonian fluid and slimming fluid. In all the simulations and experimental validations, geometric similarity was maintained with the existing conditions in the plant.

An analysis of mesh independence was carried out, comparing meshes with an increase of twice the number of elements, in which the one with the least variability of the hydrodynamic properties with respect to the previous one was chosen. Once the independent mesh was obtained, the speed fields, the dependence of the power numbers $\left.\mathrm{N}_{\mathrm{P}}\right)$ and pumping numbers $\left(\mathrm{N}_{\mathrm{Q}}\right)$ of each of the impellers under study were obtained at different operating conditions similar to those existing in the plant.

It was found that in turbulent regime for both Newtonian and non-Newtonian fluid, the power number is higher for the PBT4 impeller and the lower for the PBT6. For both fluids, the pumping number was higher for the PBT4 impeller and the lowest was obtained for the PBT6. The mixing effectiveness ratio $\left(\mathrm{N}_{\mathrm{Q}} / \mathrm{N}_{\mathrm{P}}\right)$ that was found is that Chemineer's HE3 impeller has the highest value for Newtonian fluid, while for non-Newtonian fluid, the values are very similar for PBT4 and HE3 impellers.

For the specific case study of this work, it was concluded that for the homogenization of a white coating manufactured in the company Axalta Coating Systems using the PBT4 and HE3 impellers they would have a very similar performance, while the PBT6 impeller would have the worst performance. Considering that the PBT4 impeller is a general purpose agitator and can be used in a large number of applications, and furthermore, it is easier to manufacture and its cost is lower, the PBT4 agitator would have a better performance than the HE3 impeller. 
CONTENIDO

1 INTRODUCCIÓN ......................................................................

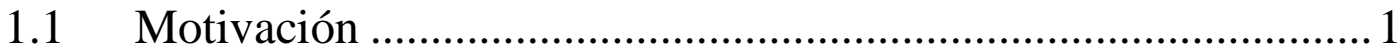

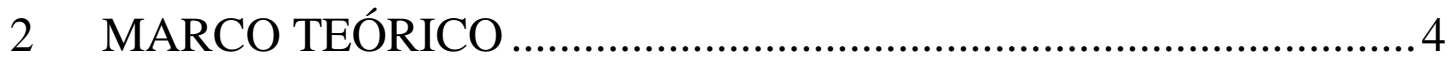

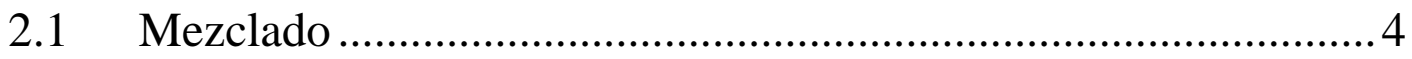

2.2 Comportamiento reológico de un fluido .................................... 7

2.2.1 Potencia inyectada en fluidos newtonianos ............................ 8

2.2.2 Bombeo y el esfuerzo cortante generado por el impulsor ........9

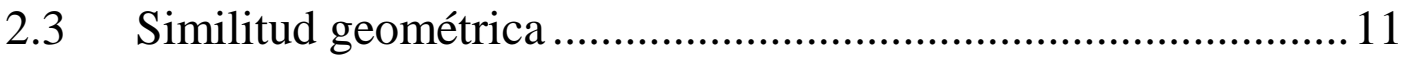

2.4 Dinámica de Fluidos Computacional ......................................... 12

2.4.1 Ecuación de continuidad ..................................................... 12

2.4.2 Ecuación de momentum ....................................................... 13

2.4.3 Turbulencia .......................................................................... 14

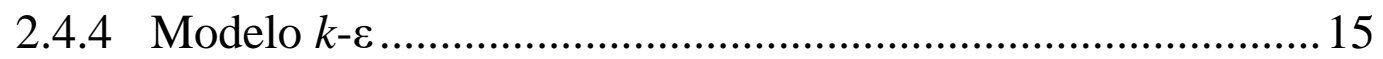

2.4.5 Modelo de múltiples marcos de referencia (MRF) ................ 16

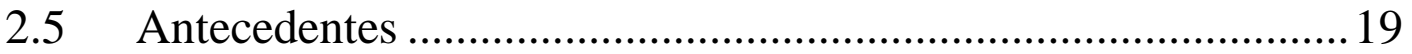

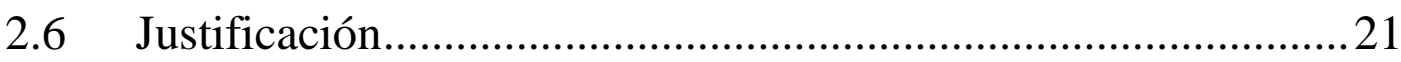

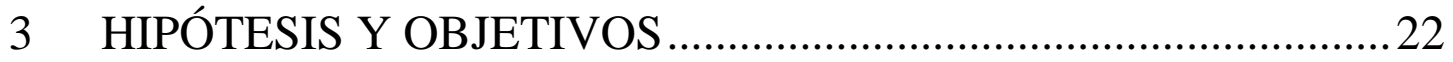

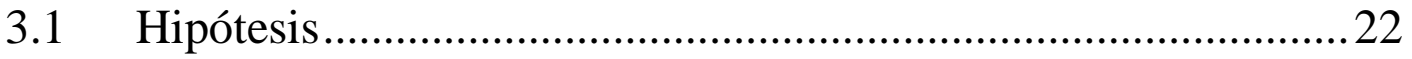

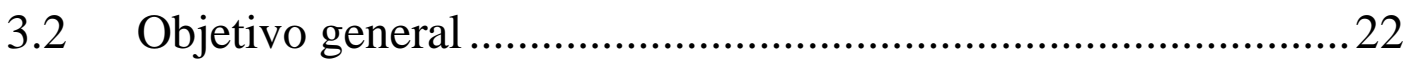

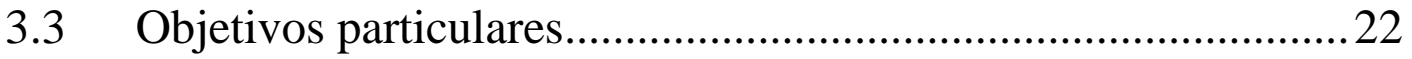

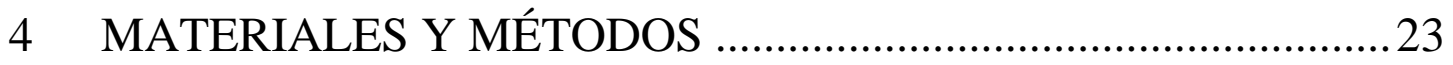




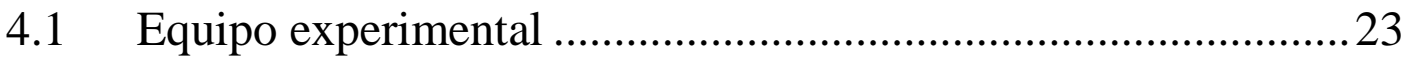

4.2 Caracterización de fluido de trabajo .........................................26

4.3 Metodología Numérica ........................................................... 27

4.3.1 Generación de la geometría y malla computacional ..............27

4.3.2 Solución de ecuaciones gobernantes ........................................ 30

4.3.3 Postprocesamiento de los datos ................................................ 32

5 ANÁLISIS Y DISCUSIÓN DE RESULTADOS …...........................33

5.1 Análisis de independencia de malla ..........................................33

5.2 Análisis de la potencia consumida ..............................................39

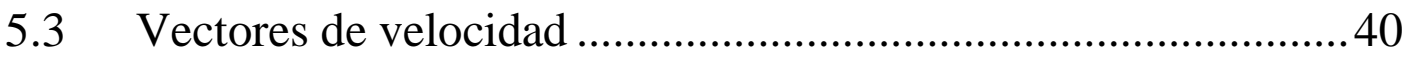

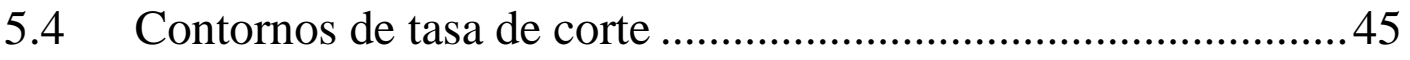

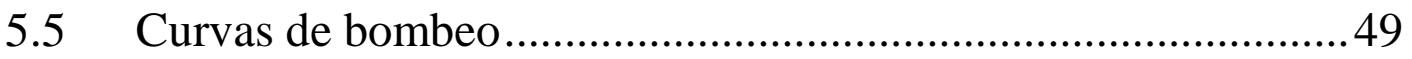

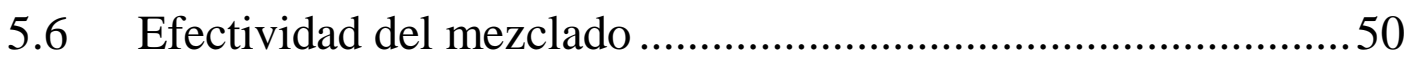

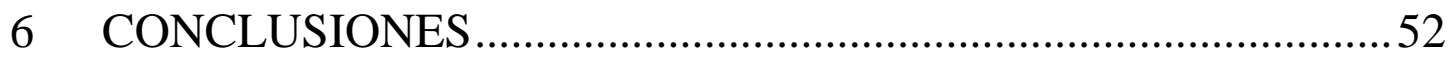

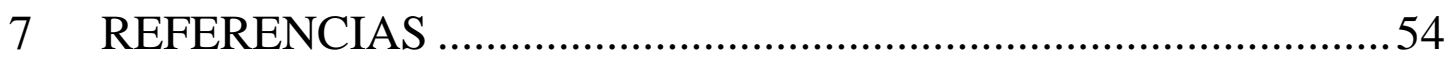




\section{ÍNDICE DE FIGURAS}

Figura 1.1. Sistemas de mezclado existentes en Axalta.

Figura 2.1. Relaciones geométricas estándares de un tanque agitado

(Derksen et al., 1999).

Figura 2.2: Ejemplos de impulsores por tipo de flujo.

5

8

9

con o sin deflectores.

Figura 2.4. Superficies donde se calcula Q y perfil de velocidad en la cercanía de la paleta del impulsor.

Figura 2.5: Representación del flujo de un fluido a trevés de un bloque (Fluent, 2018).

Figura 2.6. Tanque de mezcla cilíndrico con un límite MRF que rodea el impulsor

Figura 4.2. Dimensiones de impulsores PBT4, PBT6 y HE3 en mm.

Figura 4.3. Curva reológica de recubrimiento blanco.

Figura 4.4. Sistema de mezclado y su malla computacional segmentada en los volúmenes de análisis. Los valores usados de C, Z y $\mathrm{T}$ son acordes a la Tabla 4.1.

Figura 5.1. Tasa de corte promedio de los impulsores a) PBT4, b)

PBT6 y c) HE3 para análisis de independencia de malla con fluido newtoniano.

Figura 5.2. Tasa de corte local de un perfil radial de los impulsores a) PBT4, b) PBT6 y c) HE3 para análisis de independencia de malla con fluido newtoniano.

Figura 5.3. Velocidad local de un perfil radial para el impulsor a) PBT4, b) PBT6 y c) HE3 para análisis de independencia de malla con fluido newtoniano.

Figura 5.4. Np vs Re experimental y numérico para los impulsores PBT4, PBT6 y HE3 del fluido newtoniano.

Figura 5.5. Potencia suministrado vs la velocidad de agitación (experimental y numérica) para los impulsores PBT4, PBT6 y HE3 usando el fluido no newtoniano.

Figura 5.6. Vectores de velocidad de los fluidos newtoniano y no newtoniano a las velocidades a) 250, b) 350, c) 450 d) 550 RPM para el impulsor PBT4.

Figura 5.7. Vectores de velocidad de los fluidos newtoniano y no newtoniano a las velocidades a) 250, b) 350, c) 450 d) $550 \mathrm{RPM}$ para el impulsor PBT6.

Figura 5.8. Vectores de velocidad de los fluidos newtoniano y no newtoniano a las velocidades a) 250, b) 350, c) 450 d) 550 RPM para el impulsor HE3.

Figura 5.9. Contornos de tasa de corte de los fluidos newtoniano y no newtoniano a las velocidades a) 250 , b) 350 , c) 450 d) 550 RPM para el impulsor PBT4.

Figura 5.10. Contornos de tasa de corte de los fluidos newtoniano y no newtoniano a las velocidades a) 250 , b) 350 , c) 450 d) 550 RPM para el impulsor PBT6. 
Figura 5.11. Contornos de tasa de corte de los fluidos newtoniano y no newtoniano a las velocidades a) 250 , b) 350 , c) 450 d) 550 RPM

para el impulsor HE3.

Figura 5.12. Relación de numero de bombeo vs Re para los impulsores

PBT4, PBT6 y HE3 del fluido newtoniano.

Figura 5.13. Bombeo por impulsor a diferentes velocidades para el fluido no newtoniano de los impulsores PBT4, PBT6 y HE3.

Figura 5.14. Relación de efectividad de mezclado vs Re para el fluido newtoniano de los impulsores PBT4, PBT6 y HE3.

Figura 5.15. Relación de efectividad de mezclado (NQ/NP) vs velocidad para el fluido no newtoniano de los impulsores PBT4, PBT6 y HE3.

\section{ÍNDICE DE TABLAS}

Tabla 2.1 Valores de parámetros de mezclado de tres impulsores.

Tabla 4.1. Relaciones geométricas adimensionales de las configuraciones analizadas

Tabla 4.2. Relación de volúmenes alrededor del impulsor

Tabla 4.3. Propiedades especificadas en Fluent.

Tabla 5.1. Número de elementos por volumen de cada malla para el impulsor PBT4.

Tabla 5.2. Número de elementos por volumen de cada malla para el impulsor PBT6.

Tabla 5.3. Número de elementos por volumen de cada malla para el impulsor HE3.

Tabla 5.4. Malla independiente por impulsor y número de elementos.

\section{NOMENCLATURA}

a Vector de dirección unitario

C Distancia del fondo del tanque al

$$
\text { impulsor }
$$

[mm]

D

Diámetro del tanque

[mm]

F Fuerzas generalizadas

$[\mathrm{N}]$

$g$

Gravedad

$\left[\mathrm{m}^{2} / \mathrm{s}\right]$

$\mathrm{H}$

Altura teórica

[mm]

$h$

Altura del impulsor

[mm]

I

Tensor identidad

$[--]$

$K_{p}$

Contante de potencia laminar

[--]

$K_{s} \quad$ Constante de Metzner y Otto

[--]

$m$

Índice de consistencia

$\mathrm{Pa} \cdot \mathrm{s}^{\mathrm{n}}$

$N$

Velocidad de agitación

$\left[\mathrm{s}^{-1}\right]$

Índice de flujo

[--] 


$\begin{array}{clc}N_{p} & \text { Número de potencia } & {[--]} \\ N_{Q} & \text { Número de bombeo } & {[--]} \\ N_{R e} & \text { Número de Reynolds } & {[--]} \\ P & \text { Potencia inyectada } & {[\mathrm{W}]} \\ Q & \text { Capacidad de bombeo } & {\left[\mathrm{m}^{3} / \mathrm{s}\right]} \\ R & \text { Radio del impulsor } & {[\mathrm{mm}]} \\ \mathrm{T} & \text { Diámetro del tanque } & {[\mathrm{mm}]} \\ \boldsymbol{u} & \text { velocidad } & {[\mathrm{m} / \mathrm{s}]} \\ v_{r} & \text { Flujo de descarga } & {[\mathrm{m} / \mathrm{s}]} \\ w & \text { Ancho de la paleta } & {[\mathrm{mm}]} \\ x, y, z & \text { Coordenadas cartesianas } & {[\mathrm{mm}]} \\ Z & \text { Altura del líquido } & {[\mathrm{mm}]}\end{array}$

\section{Abreviaturas}

CFD Dinámica de Fluidos computacional

PBT4 Impulsor de 4 paletas planas inclinadas

PBT6 Impulsor de 6 paletas planas inclinadas

$\begin{array}{cl}\text { HE3 } & \text { Impulsor de } 3 \text { paletas inclinadas de } \\ \text { RPM } & \text { Remineer } \\ \text { VR } & \text { Volumen de líquido restante } \\ \text { VC } & \text { Volumen barrido por las cuchillas } \\ \text { V1 to V8 } & \text { Volúmenes de fluido alrededor del } \\ & \text { impulsor }\end{array}$

\section{Letras griegas}

$\begin{array}{clc}\dot{\gamma} & \text { Tasa de corte local } & {\left[\mathrm{s}^{-1}\right]} \\ \dot{\gamma}_{\text {prom }} & \text { Tasa de corte promedio } & {\left[\mathrm{s}^{-1}\right]} \\ \mu & \text { Viscosidad } & {[\mathrm{Pa} \cdot \mathrm{s}]} \\ \Im & \text { Torque } & {[\mathrm{N} \cdot \mathrm{m}]} \\ \rho & \text { Densidad } & {\left[\mathrm{Kg} \cdot \mathrm{m}^{-3}\right]} \\ \omega & \text { Velocidad angular } & {\left[\mathrm{s}^{-1}\right]} \\ \tau & \text { Tensor de esfuerzos viscosos } & {[\mathrm{Pa}]} \\ \phi & \text { Cantidad escalar } & {[--]} \\ \phi_{f} & \text { Valor de } \phi \text { a través de } f & {[--]}\end{array}$




\section{INTRODUCCIÓN}

\subsection{Motivación}

Axalta es una compañía global de manufactura de recubrimientos enfocada en proporcionar a sus clientes soluciones innovadoras y sostenibles. La empresa tiene más de 150 años de experiencia en la industria de recubrimientos y está presente en alrededor de 130 países, entre ellos México. Axalta continúa buscando formas de atender a sus más de 100,000 clientes con los mejores recubrimientos, sistemas de aplicación y tecnología (Axalta Coating Systems, 2019). Adicionalmente, el panorama para México en este sector lo coloca en el segundo lugar como productor y consumidor de pintura en américa latina y continua creciendo con muy buenas expectativas para la economía mexicana (Chaverra, 2016). Por lo anterior, la empresa cuenta con programas de mejora continua de sus productos y procesos. Siguiendo esta línea de pensamiento, en el presente trabajo se plantea un estudio usando herramientas de Dinámica de Fluidos Computacional (CFD, por sus siglas en inglés) con el objetivo de analizar la eficiencia de mezclado en los tanques agitados usados para la producción de un recubrimiento blanco base agua en una planta de Axalta México.

En Axalta México existen varias configuraciones de impulsores en los sistemas de mezclado instalados para manufacturar recubrimientos dirigidos a la industria automotriz, algunos de los cuales se muestran en la Figura 1.1. Los sistemas con impulsores tipo ancla son comúnmente utilizados para procesar materiales de media a alta viscosidad, y debido a la posición del impulsor en el tanque es posible mezclar lotes pequeños. Los sistemas agitados de flujo predominantemente axial son los más utilizados para los recubrimientos de media o baja viscosidad como son los materiales de la industria de repintado y automotriz. Dentro de este tipo de sistemas, los deflectores son los que facilitan el mezclado y una homogeneización completa en menor tiempo. 


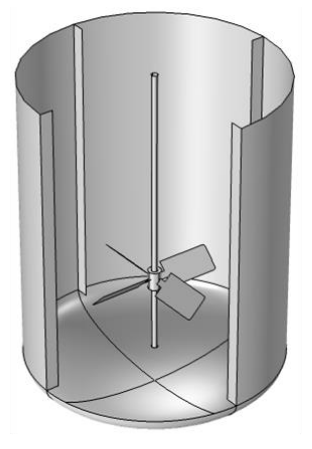

Impulsor axial

PBT4

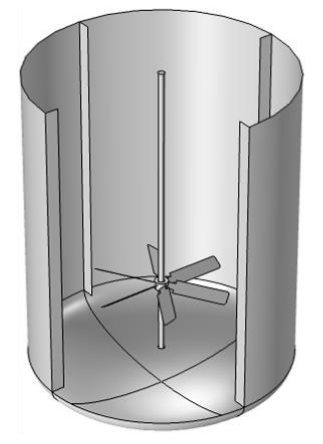

Impulsor axial

PBT6

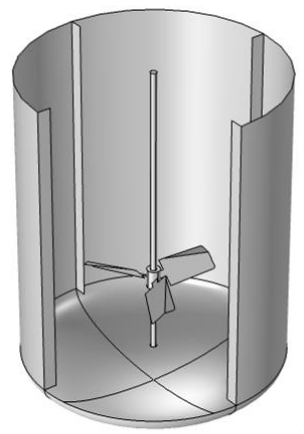

Impulsor axial

HE3

Figura 1.1. Sistemas de mezclado existentes en Axalta.

Actualmente se desconoce el comportamiento hidrodinámico de las diferentes configuraciones en los tanques disponibles y el impacto que tiene cada una de ellas sobre el proceso de manufactura de los recubrimientos. Debido a este desconocimiento, la toma de decisiones posterior a la evaluación de la calidad, color y desempeño de los materiales no resulta eficaz, estos conlleva a que las muestras evaluadas en repetidas ocasiones no son representativas. Cuando la toma de decisiones no es la adecuada, se presentan detractores para la liberación y envase de los materiales como reprocesos que generan un incremento en el tiempo de proceso de cada producto manufacturado, impactando directamente en el costo de producción y número de recursos necesarios.

Por otro lado, los productos que actualmente se procesan en los tanques de mezclado tienen comúnmente un comportamiento reológico no newtoniano, el cual no se ha caracterizado y se desconoce el efecto de la reología en la eficiencia de mezclado. En el presente trabajo se desarrolla una metodología sistemática con el fin de mejorar el entendimiento de los sistemas de mezclado existentes. Dicha metodología consiste primero en caracterizar la hidrodinámica de los sistemas de mezclado de escala laboratorio con una geometría similar a los de planta, y posteriormente incidir en la mejora de los procesos de mezclado existentes en planta usando resultados experimentales y numéricos del tanque de escala de laboratorio.

Con el fin de tener el mayor impacto en el proceso de manufactura, se eligió un recubriendo blanco el cual es uno de los productos con mayor volumen de fabricación, y 
posteriormente se estudió el comportamiento hidrodinámico de dicho recubrimiento en tres configuraciones de tanques de mezclado instalados en la planta con impulsores de flujo axial, equipos donde es comúnmente manufacturado. Adicionalmente, se realizaron mediciones experimentales de potencia para validar los resultados obtenidos mediante simulaciones CFD.

La eficiencia de mezclado se realiza comparando para cada configuración de tanque de mezclado los números adimensionales de bombeo y de potencia, y la relación entre ambos, como lo sugiere Nienow (1996). Usando este criterio, se determinó cual es la geometría que tendría una mejor eficiencia de mezclado en el proceso de planta. Dado que el estudio se realizó con sistemas de mezclado geométricamente similares a los existentes en planta, los resultados obtenidos se pueden extrapolar a la fabricación de recubrimientos con reología similar en planta. 


\section{MARCO TEÓRICO}

\subsection{Mezclado}

El mezclado es una operación unitaria que se puede definir como un aumento de la homogeneidad para lograr un resultado deseado de algún proceso. Esta condición de homogeneidad que se busca puede ser de concentración, fases o temperatura. Algunos de los problemas que se pueden presentar si la mezcla no es la adecuada es no obtener la calidad, rendimiento y atributos requeridos del producto final, por lo cual éste puede ser rechazado para su venta al público.

Lo anterior incrementa el costo de operación debido a retrabajos o procesos alternos que se deben realizar para satisfacer la calidad final requerida del producto, y además puede impactar significativamente en la comercialización del producto (Paul et al., 2004). Para poder determinar el impulsor idóneo para cada aplicación específica, el análisis debe considerar además el desempeño final que se desea en el mezclado de un producto específico.

De acuerdo con el Manual de Mezclado Industrial (Paul et al., 2004), los impulsores que se recomienda en operaciones la homogeneización de líquidos miscibles son de flujo axial para un régimen de transición a turbulento. Los tanques agitados comúnmente tienen forma cilíndrica y están provistos de un eje vertical en el centro del tanque en cuya parte final se instala(n) el (o los) agitadores. La parte superior del tanque puede estar abierta a la atmósfera o cerrada. Las relaciones geométricas del tanque varían dependiendo de la naturaleza del problema de agitación. Sin embargo, en muchas situaciones se utiliza un diseño estandarizado como el que se muestra en la Figura 2.1. En el diseño estándar, la altura del líquido (Z) es aproximadamente igual al diámetro del tanque (T). El diámetro del impulsor (D) suele ser un tercio del diámetro del tanque. También es común encontrar en un tanque agitado mecánicamente accesorios como bafles, tubos de entrada y salida, serpentines, chaquetas y sondas para instalar instrumentos de medición. 


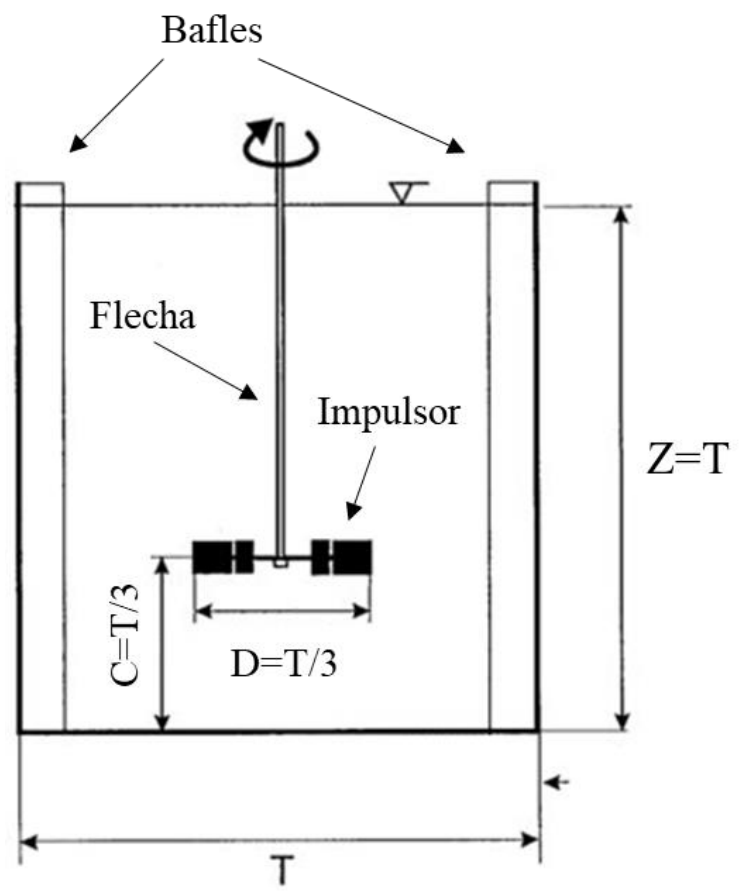

Figura 2.1. Relaciones geométricas estándares de un tanque agitado (Derksen et al., 1999).

En el régimen de flujo turbulento, la presencia o ausencia de bafles tiene un efecto importante sobre la agitación. Si no hay deflectores, el fluido tiende a moverse en una trayectoria circular y la componente axial de la velocidad resulta pequeña. Esto provoca que el mezclado axial sea deficiente y ocurra la formación de un vórtice. Al instalar deflectores se evita que el fluido se mueva de forma circular y se inhibe la formación del vórtice, así, el flujo axial y la circulación del fluido por unidad de tiempo a través de la región del impulsor aumenta, y se mejora el mezclado. Por otro lado, en el régimen de flujo laminar reptante, la formación del vórtice no tiene impacto sobre los parámetros hidrodinámicos, esto se debe a que su formación se limita a las inmediaciones del eje de rotación, además el uso de bafles puede ocasionar zonas muertas que son indeseable en un proceso de mezclado.

En la actualidad existe una división que engloba tres grupos grandes de impulsores que son utilizados ampliamente en la industria, esta clasificación se basa en el tipo de flujo que genera como se muestra a continuación, ejemplos de algunos impulsores por tipo de flujo se presentan en la Figura 2.2. 
1. Impulsores de flujo axial: son utilizados en su mayoría para mezcla de fluidos miscibles, suspensión de sólidos, incorporación o dispersión de sólidos y transferencia de calor.

2. Impulsores de flujo radial: este tipo de impulsores generan un mayor corte que los de flujo axial y un menor bombeo, además de ser recomendados para fluidos de baja a media viscosidad de una sola fase o múltiples fases y son más efectivos para la dispersión de sistemas gas-líquido y líquido-líquido.

3. Impulsores de alta eficiencia: se desarrollaron para mantener un flujo axial importante con un bajo corte. Tienen tres o cuatro paletas con un doblez, suelen estar curvadas y a veces, son fabricadas con bordes delanteros redondeados con el fin de incrementar la componente axial de la velocidad.

Impulsores de flujo axial
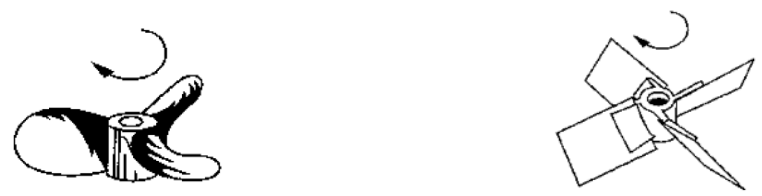

Propela marina

Paletas inclinadas a $45^{\circ}$

Impulsores de flujo radial
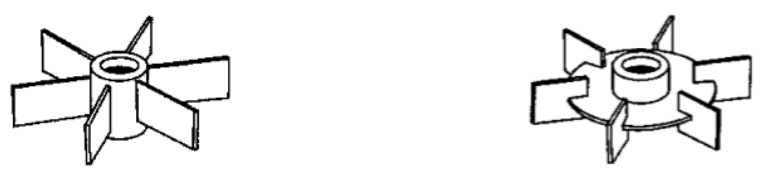

Paletas planas

Con disco (Rushton)

Impulsores de alta eficiencia

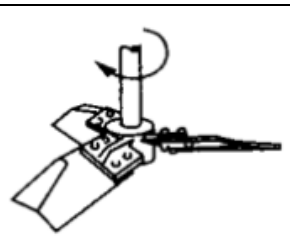

Chemineer HE3

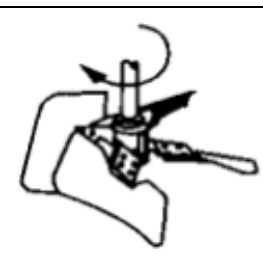

Lightnin A315

Figura 2.2: Ejemplos de impulsores por tipo de flujo. 


\subsection{Comportamiento reológico de un fluido}

El patrón de flujo generado por un impulsor se ve afectado por la viscosidad del fluido. La viscosidad es la propiedad del fluido que se define como la resistencia a fluir a través de fuerzas internas y atracción molecular. Los fluidos poco viscosos presentan poca resistencia al flujo por lo que requieren cantidades relativamente bajas de energía por unidad de volumen para alcanzar la homogeneidad. Sin embargo, fluidos muy viscosos amortiguan la energía mecánica trasmitida desde el impulsor por lo que requieren cantidades relativamente grandes de potencia por unidad de volumen para alcanzar un estado de flujo adecuado (Holland, 1966).

Los fluidos pueden clasificarse en dos grandes grupos: fluidos newtonianos y fluidos no newtonianos. La viscosidad de los fluidos newtonianos es independiente del esfuerzo cortante. Así, aunque el esfuerzo y la tasa de corte varíen a lo largo del flujo del fluido, la viscosidad será la misma en todos los puntos del fluido. En contraste, la viscosidad de un fluido no newtoniano (llamada comúnmente viscosidad aparente) dependerá de la magnitud del esfuerzo o la tasa de corte (Mott, 1996) al que esté sometido el fluido. El efecto de la tasa de corte en la viscosidad aparente determinará el perfil de viscosidad dentro del tanque.

El comportamiento reológico más común en procesos de manufactura de pinturas es el adelgazamiento al corte (i.e. fluido pseudoplástico), donde incrementando la tasa de corte, la viscosidad del material decrece. El comportamiento reológico dependerá de la naturaleza química y física de los materiales utilizados, en el caso de las pinturas y recubrimientos generalmente mostrarán este tipo de comportamiento debido a que las formulaciones de pinturas contienen tanto polímeros (en solución) como altas concentraciones de partículas. Por otro lado, los fluidos con un engrosamiento por aumento de la tasa de corte se conocen como dilatantes, por lo que la viscosidad aumenta al incrementar el esfuerzo cortante. Este comportamiento se puede observar con materiales que contienen una alta concentración de partículas, por ejemplo, las suspensiones de pigmentos. La industria de recubrimientos a menudo explota este comportamiento en la fabricación de pinturas utilizando concentrados de pigmento que muestran un engrosamiento por corte $y$, por lo tanto, cuando se las hace fluir rápidamente muestran una viscosidad muy alta (Marrion, 2004). 
La ecuación que relaciona el esfuerzo de corte y la rapidez de deformación para un fluido ley de potencia es la siguiente:

$$
\tau=m \dot{\gamma}^{n}
$$

donde $m$ y $n$ son constantes y se les conoce como índice viscoso e índice de consistencia respectivamente. Cuando $n<1$ se trata de un fluido adelgazante y cuando $n>1$ se trata de un fluido dilatante (Bird et al., 2006).

\subsubsection{Potencia inyectada en fluidos newtonianos}

En un tanque agitado mecánicamente, el consumo de potencia es quizás la medida más fundamental que se puede hacer en este tipo de sistemas, ya que muchas reglas de escalamiento dependen en gran medida de la entrada de potencia específica o consumo de potencia, $P$, de un impulsor. El consumo de potencia para un sistema de mezclado determinado, depende de variables como la densidad del fluido $(\rho)$, su viscosidad $(\mu)$, la fuerza de gravedad $(g$ ) la velocidad de agitación (N), el diámetro del impulsor (D), el diámetro del tanque $(\mathrm{T})$, la altura del líquido $(\mathrm{Z})$, y otras características geométricas del sistema (García-Cortés and Jáuregui-Haza, 2006):

$$
P=f(\rho, \mu, g, N, D, T, Z, \text { otras características geométricas })
$$

Debido a la complejidad de la geometría de los componentes del sistema de agitación (recipiente, impulsor, deflectores, difusores, serpentines, etc.,), la obtención de una ecuación analítica para el cálculo de la potencia resulta compleja. Sin embargo mediante un análisis dimensional puede quedar expresada en función números adimensionales:

$$
\frac{P}{\rho N^{3} D^{5}}=f\left(\frac{\rho N D^{2}}{\mu}, \frac{N^{2} D}{g}, \frac{T}{D}, \frac{Z}{D}, \text { otras relaciones geométricas }\right)
$$

dónde pueden identificarse los siguientes números adimensionales (Martínez-de Jesús et al., 2018):

$$
\text { Número de Potencia: } N_{P}=\frac{P}{\rho N^{3} D^{5}}
$$


Número de Reynolds: $R e=\frac{\rho N D^{2}}{\mu}$

Número de Froude: $F r=\frac{N^{2} D}{g}$

El $N_{P}$ es una relación entre la potencia que consume el agitador y la inercia que se le induce al fluido. El Re representa la relación entre las fuerzas inerciales y las viscosas y el Fr relaciona las fuerzas inerciales con la fuerza de gravedad. La dependencia del $\mathrm{N}_{\mathrm{P}}$ respecto del Fr, sólo es importante cuando existe una importante formación del vórtice, lo cual se presenta generalmente en sistema sin deflectores a Re>300.

La Figura 2.3 muestra la dependencia del $N_{P}$ respecto del Re se conoce como "curva de potencia". De esta figura se puede observar que en Re menores a 300 las curvas del sistema agitado con o sin deflectores se sobreponen. En cambio en el régimen turbulento, régimen de estudio en este trabajo, el $N_{P}$ de un sistema con deflectores es mayor en comparación a un sistema sin ellos, además el valor numérico es constante a lo largo de todo el régimen (Oldshue, 1983).

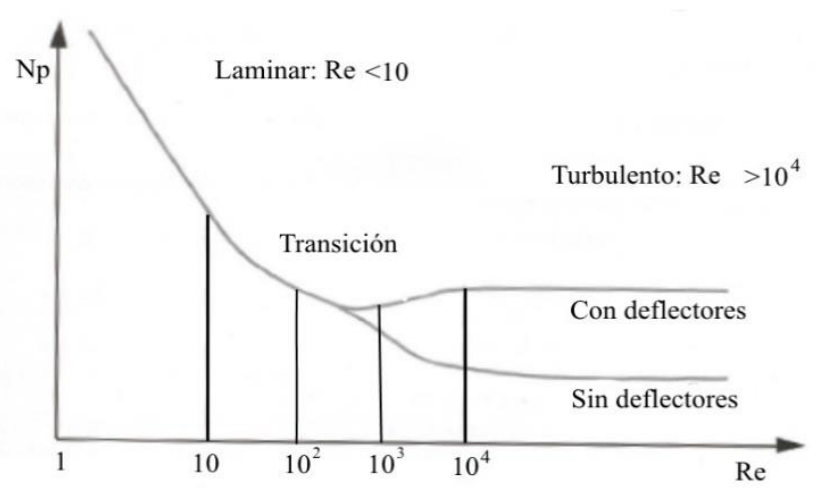

Figura 2.3. Curva de potencia ( $\mathrm{N}_{\mathrm{P}}$ vs $\mathrm{Re}$ ) para un tanque cilíndrico con o sin deflectores.

2.2.2 Bombeo y el esfuerzo cortante generado por el impulsor

Un impulsor es esencialmente una bomba, del total de la energía que el impulsor suministra al fluido, una parte de la potencia suministrada se destina a la generación de bombeo (Q), que produce la circulación interna del fluido, otra parte se utiliza para producir el $\tau$ que también es expresado como una altura teórica, H (Holland and Chapman, 1966). Q es 
proporcional a la velocidad de agitación y al diámetro del impulsor, ecuación (2.7). H depende de la velocidad de agitación y del diámetro del impulsor, ecuación (2.8).

$$
\begin{aligned}
& Q \propto N D^{3} \\
& H \propto \rho N^{2} D^{2}
\end{aligned}
$$

Entonces, la potencia consumida puede obtenerse multiplicando la capacidad de bombeo y la altura:

$$
P=N_{P}\left(\rho N^{2} D^{2}\right)\left(N D^{3}\right)
$$

en dónde el factor de proporcionalidad es el número de potencia, $\mathrm{N}_{\mathrm{P}}$. Considerando una potencia dada, de la ecuación (2.9) puede deducirse que, si el diámetro del impulsor se incrementa, una mayor proporción de la potencia se dirige a la generación de Q, y en menor proporción se destinará para la generación $\tau$. Mientras, para un mismo diámetro de impulsor, al incrementar $\mathrm{N}$, una mayor proporción de la potencia se destinará para la generación de $\tau$, y en menor proporción para Q. También resulta que, si un impulsor de diámetro grande rota a velocidades bajas, producirá altos valores de Q y poco $\tau$, en contraste, si un impulsor pequeño gira a altas velocidades producirá poco bombeo y un alto corte.

La capacidad de bombeo del impulsor puede determinarse mediante el flujo normal al plano de descarga del impulsor, ya sea radial o normal. En el caso de impulsores de tipo axial deberá calcularse el flujo que atraviesa el área que barre el impulsor en la Figura 2.4.

$$
Q=2 \pi r \int v_{r} d y
$$
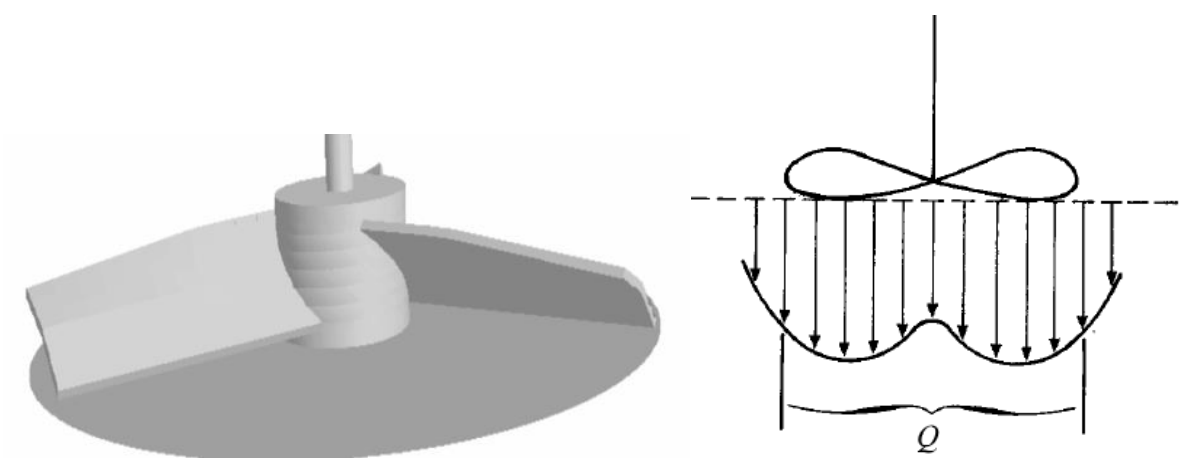

Figura 2.4. Superficies donde se calcula Q y perfil de velocidad en la cercanía de la paleta del impulsor. 
El número de bombeo es la relación de la capacidad de bombeo y el flujo volumétrico, y se define como:

$$
N_{Q}=\frac{Q}{N D^{3}}
$$

Generalmente, la relación $\mathrm{N}_{\mathrm{Q}} / \mathrm{N}_{\mathrm{P}}$ puede utilizarse para comparar la eficiencia de diferentes impulsores (Ramírez-Muñoz et al., 2017).

\subsection{Similitud geométrica}

En muchas aplicaciones de ingeniería, la experimentación es el único método de obtener información confiable ya que no resulta fácil implementar y solucionar modelos numéricos del tanque real. En la mayoría de los experimentos, para ahorrar tiempo y dinero, las pruebas se realizan en un modelo a escala geométrica, en lugar de en un prototipo de tamaño real. En tales casos, se debe tener especial cuidado de escalar adecuadamente los resultados (Zlokarnik, 2006). Para este fin se usa el análisis dimensional, el cual es útil en todas las disciplinas, aunque éste ha tenido mucho auge en la dinámica de fluidos, y especialmente cuando se requiere diseñar y realizar experimentos.

La similitud geométrica se refiere a que un modelo a escala pequeña debe tener la misma forma geométrica que el prototipo a escala real, y se puede escalar por algún factor de escala constante. La ventaja que nos ofrece el análisis por similitud geométrica es tiempo de análisis y en el caso de CFD el tiempo de cómputo, ya que es mucho más rápido y menos costoso computacionalmente analizar un volumen pequeño de nivel laboratorio que un volumen de nivel industrial.

El estudio realizado en este trabajo se basó en reproducir en el laboratorio la geometría de un tanque agitado instalado en planta, del cual se consideraron las relaciones geométricas diámetro del impulsor a diámetro del tanque (D/T), altura del líquido de trabajo a diámetro del tanque $(\mathrm{Z} / \mathrm{T})$ y distancia del impulsor con respecto al diámetro del tanque $(\mathrm{C} / \mathrm{T})$. Todas estas relaciones geométricas fueron las mismas entre el sistema de agitación prototipo de escala de planta y el sistema de agitación de escala laboratorio usado en este estudio. 


\subsection{Dinámica de Fluidos Computacional}

Aunque la agitación en un tanque agitado es una de las operaciones más comunes en la industria, el modelado y simulación de los sistemas de mezclado no resulta sencillo. El modelado de un tanque agitado usando dinámica de fluidos computacional (CFD) requiere la consideración de muchos aspectos del proceso (Paul et al., 2004).

Primero, cualquier modelo computacional requiere que el dominio de interés, en este caso el volumen ocupado por el fluido dentro del recipiente cilíndrico, se describa mediante una cuadrícula o malla computacional. En estas celdas es donde se calculan y almacenan las variables específicas del problema. La malla computacional debe ajustarse a los contornos del recipiente (pared del recipiente y deflectores o bafles) y sus componentes internos (eje de rotación y agitador), incluso si los componentes son geométricamente complejos. Por otro lado, el movimiento del impulsor en el tanque debe tratarse de una manera especial considerando si el tanque contiene deflectores u otros elementos internos. El tratamiento especial empleado afecta tanto la construcción de la malla computacional como el método de solución utilizado para obtener numéricamente el campo de flujo en cada celda (Anderson et al., 2013).

Se han desarrollado numerosos modelos y técnicas de solución a lo largo de los años para ayudar a describir una amplia variedad del movimiento fluido en un tanque agitado. Aunque el enfoque principal está en modelos específicos que son relevantes para el análisis de procesos de mezcla, también se discuten varios modelos avanzados para flujos más complejos.

\subsubsection{Ecuación de continuidad}

La ecuación de continuidad es una descripción de conservación de la masa. Vamos a considerar el flujo de un fluido con una densidad $(\rho)$ a través de las seis caras de un bloque 
rectangular con lados de longitud $x_{1}, x_{2}$ y $x_{3}$ y componentes de velocidad $U_{1}, U_{2}$ y $U_{3}$ en cada una de las tres direcciones de coordenadas como se muestra en la Figura 2.5.

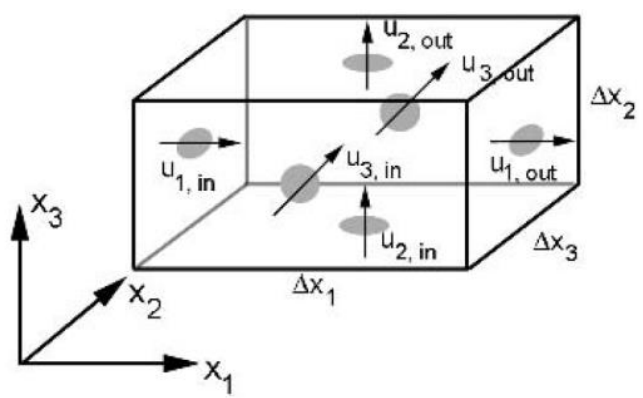

Figura 2.5: Representación del flujo de un fluido atreves de un bloque (Fluent, 2018).

Despreciando la acumulación de masa en el sistema, la masa que fluye a través de las seis caras debe ser cero (estado estacionario):

$$
\begin{gathered}
\rho(U 1, \text { out }-U 1, \text { in })(x 2 x 3)+\rho(U 2, \text { out }-U 2, \text { in })(x 1 x 3)+\rho(U 3, \text { out }- \\
U 3, \text { in })(x 1 x 2)=0
\end{gathered}
$$

En una forma diferencial, y considerando la densidad constante, la ecuación anterior se expresa como:

$$
\frac{\partial U_{1}}{\partial x_{1}}+\frac{\partial U_{2}}{\partial x_{2}}+\frac{\partial U_{3}}{\partial x_{3}}=0
$$

\subsubsection{Ecuación de momentum}

La ecuación de momentum es una ecuación vectorial que describe la evolución de la cantidad de movimiento a través del flujo de un fluido. Las tres ecuaciones de momentum en conjunto con la ecuación de continuidad se denominan colectivamente ecuaciones de Navier-Stokes. Además del transporte de momentum por convección y difusión, también intervienen varias fuentes de momentum :

$$
\frac{\partial\left(\rho U_{i}\right)}{\partial t}+\frac{\partial}{\partial x_{j}}\left(\rho U_{i} U_{j}\right)=-\frac{\partial p}{\partial x_{i}}+\frac{\partial}{\partial x_{j}}\left[\mu\left(\frac{\partial U_{i}}{\partial x_{j}}+\frac{\partial U_{j}}{\partial x_{i}}-\frac{2}{3} \frac{\partial U_{k}}{\partial x_{k}} \delta_{i j}\right)\right]+\rho g_{i}+F_{i}
$$

En la ecuación anterior los términos de convección están a la izquierda. Los términos en el lado derecho son el gradiente de presión (fuerzas de presión), la divergencia del tensor 
de esfuerzos viscosos (o fuerzas viscosas), responsables de la difusión del momento, la fuerza gravitacional, y otras fuerzas generalizadas, respectivamente.

\subsubsection{Turbulencia}

Se han desarrollado diversos parámetros adimensionales para el estudio de la dinámica de los fluidos que se utilizan para clasificar los diferentes regímenes de flujo. Estos parámetros, o números, se usan para clasificar los fluidos y las características del flujo. Uno de los más comunes es el número de Reynolds, definido como la relación de las fuerzas de inercia, o las que dan lugar al movimiento del fluido, a las fuerzas de fricción, o las que tienden a disminuir la velocidad del fluido. En dominios geométricamente similares, dos fluidos con el mismo número de Reynolds deben comportarse de la misma manera.

En el régimen turbulento, se producen fluctuaciones en la velocidad media y otras variables, y para que el modelo pueda proporcionar resultados significativos, su efecto debe incorporarse al modelo CFD. Esto se hace mediante el uso de un modelo de turbulencia. Este modelado resulta ser mucho menos costoso que la realización de experimentos ya que se pueden extraer datos mucho más detallados que la disponible en la experimentación.

Existen muchos modelos de turbulencia y la diferencia entre ellos radica en la complejidad de su solución y la representación física. Estos modelos pueden o no utilizar promedios en el tiempo o de estructuras específicas. Este método consiste en una aproximación basada en un razonamiento estadístico, análisis dimensional, evidencia experimental o modelado.

Algunos de estos modelos de turbulencia son:

- Modelo de 2 ecuaciones como $k-\varepsilon$ que asume que las turbulencias es isotrópica.

- Full Reynolds stress models (ASM, RSM o DSM): modela la anisotropía en el flujo con las seis componentes del tensor de esfuerzos de Reynolds en su forma promediada en el tiempo.

- Large eddy simulations (LES): modela las escalas de turbulencia anisotrópicas más grandes siguiendo su movimiento directamente que varía en el tiempo. 
- Direct numerical simulations (DNS): resuelve el campo de flujo en cada instante en el tiempo, almacenando registros tridimensionales completos de la velocidad fluctuante mediante la forma instantánea de las ecuaciones de Navier-Stokes.

Entre más precisa sea la solución que ofrece el modelo de turbulencia, mayor será el tiempo de cómputo y el costo de procesamiento. Para simplificar el modelado, Reynolds planteó una forma promediada en el tiempo de las ecuaciones de Navier-Stokes. Estas ecuaciones son conocidas como las ecuaciones promediadas de Reynolds o RANS que relacionan cantidades promediadas en el tiempo, no así valores instantáneos dependientes del tiempo.

\subsubsection{Modelo $k-\varepsilon$}

El modelo $k$ - $\varepsilon$ es uno de una familia de modelos de dos ecuaciones para las cuales se deben resolver dos ecuaciones de transporte adicionales para calcular los esfuerzos de Reynolds. Es un modelo robusto, lo que significa que es computacionalmente estable, incluso en presencia de un fenómeno físico muy compleja. Es aplicable a una amplia variedad de flujos turbulentos y ha servido a la comunidad de modelado de fluidos durante muchos años (Wendt, 2008). Es semiempírico, se basa en gran parte en observaciones de flujos de alto número de Reynolds. Las dos ecuaciones de transporte que deben resolverse para este modelo son para la energía cinética de la turbulencia, $k$, y la tasa de disipación de la turbulencia, $\varepsilon$ :

$$
\begin{aligned}
& \frac{\partial(\rho k)}{\partial t}+\frac{\partial}{\partial x_{i}}\left(\rho U_{i} k\right)=\frac{\partial}{\partial x_{i}}\left(\mu+\frac{\mu_{t}}{\sigma_{k}}\right) \frac{\partial k}{\partial x_{i}}+G_{k}-\rho \varepsilon \\
& \frac{\partial(\rho \varepsilon)}{\partial t}+\frac{\partial}{\partial x_{i}}\left(\rho U_{i} \varepsilon\right)=\frac{\partial}{\partial x_{i}}\left(\mu+\frac{\mu_{t}}{\sigma_{\varepsilon}}\right) \frac{\partial \varepsilon}{\partial x_{i}}+C_{1} \frac{\varepsilon}{k} G_{k}+C_{2} \rho \frac{\varepsilon^{2}}{k}
\end{aligned}
$$

Las cantidades $\mathrm{C}_{1}, \mathrm{C}_{2}, \sigma_{\mathrm{k}}$ y $\sigma_{\varepsilon}$ son constantes empíricas. La cantidad $\mathrm{G}_{\mathrm{k}}$ que aparece en ambas ecuaciones es un término de generación para turbulencia. Contiene productos de gradientes de velocidad y también depende de la viscosidad turbulenta: 
$G_{k}=\mu_{t}\left(\frac{\partial U_{i}}{\partial x_{j}}+\frac{\partial U_{j}}{\partial x_{i}}\right) \frac{\partial U_{j}}{\partial x_{i}}$

Para resumir el proceso de solución para el modelo $k$ - $\varepsilon$, las ecuaciones de transporte se resuelven para la energía cinética turbulenta y la tasa de disipación. Las soluciones para $k$ y $\varepsilon$ se utilizan para calcular la viscosidad turbulenta, $\mu_{t}$. Usando los resultados para $\mu_{t}$ y $k$, las tensiones de Reynolds se pueden calcular a partir de la hipótesis de Boussinesq para la sustitución en las ecuaciones de momento. Una vez que se han resuelto las ecuaciones de impulso, los nuevos componentes de velocidad se utilizan para actualizar el término de generación de turbulencia, $\mathrm{G}_{\mathrm{k}}$, y el proceso se repite.

$$
\mu_{t}=\rho C_{\mu} \frac{k^{2}}{\varepsilon}
$$

Para obtener buenos resultados la geometría del impulsor que se quiere analizar se debe hacer mediante una simulación 3D. Existen varios métodos de solución disponibles para incorporar el movimiento del impulsor en donde la cuadrícula computacional utilizada debe adaptarse al método de solución empleado.

\subsubsection{Modelo de múltiples marcos de referencia (MRF)}

En un tanque agitado mecánicamente se debe tomar en cuenta el efecto de la rotación del impulsor. Existen diversos enfoques para modelar el movimiento del impulsor los cuales se pueden agrupar en no estacionarios y estacionarios (Joshi et al., 2011). Los métodos no estacionarios pueden capturar completamente la interacción impulsor-fluido mediante la simulación del movimiento de la flecha y el impulsor a través de mallas deslizantes, mallas móviles o puntos virtuales de control. El método no estacionario más común es el enfoque de mallas deslizantes o Sliding-mesh (SM), en el cual se divide el dominio del tanque en dos secciones, una interna que contiene al impulsor y una externa en donde estarán el resto de fluido y demás piezas que estáticas del tanque (bafles, serpentines, etc.). El domino externo se mantiene fijo, mientras que el dominio interno gira a la velocidad de rotación del impulsor y la comunicación entre ambos se realiza mediante una interpolación en la interface de la mallas (Murthy et al., 1994). 
A pesar de la alta precisión de los métodos no estacionarios su costo computacional es muy elevado, una alternativa son los métodos estacionarios en los cuales el impulsor se mantiene estático en la simulación y el campo de velocidades en rotación puede ser aproximado usando los siguientes enfoques (Joshi et al., 2011): condiciones de Frontera de Impulsor (IBC, Impeller Boundary Condition), termino Fuente (SS, Source-Sink approach), o marcos de referencia múltiples (MRF, Multiple Reference Frame). Este último ha sido ampliamente estudiado y aplicado en numerosos trabajos, (Jaworski and Dudczak, 1998; Bujalski et al., 2002; Ramírez-Gómez et al., 2015; De La Concha-Gómez et al., 2019) mostrando que es capaz de proporcionar resultados comparables a los obtenidos en enfoques como el SM pero con un tiempo de cómputo de un orden de magnitud menor (Oshinowo et al., 1999), con la limitante de que la interacción con los bafles o demás piezas estáticas sea baja (Oshinowo et al., 2000).

En el modelo MRF se basa en la posibilidad de usar más de un marco de referencia giratorio en una simulación. Este enfoque de estado estable permite el modelado de tanques con agitación desconcertados y tanques con otros componentes internos rotativos o estacionarios. Se usa un marco rotativo para la región que contiene los componentes rotativos, mientras que un marco estacionario se usa para regiones estacionarias. En el marco giratorio que contiene un impulsor, el impulsor está en reposo. En el marco estacionario que contiene las paredes y los deflectores del tanque, las paredes y los deflectores están en reposo. El hecho de que se puedan usar múltiples marcos de referencia significa que múltiples ejes impulsores en un tanque rectangular se pueden modelar con marcos rotativos separados (con frecuencias de rotación separadas) mientras que el espacio restante se puede modelar con un marco estacionario, tal como se muestra en la Figura 2.6.

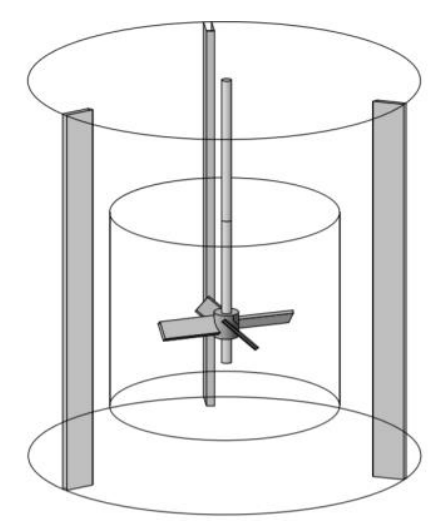


Figura 2.6. Tanque de mezcla cilíndrico con un límite MRF que rodea el impulsor

La malla utilizada para una solución MRF debe tener una superficie de revolución perfecta que rodea cada marco giratorio. Las ecuaciones de impulso dentro del marco giratorio se resuelven en el marco del impulsor cerrado, mientras que las que están fuera del marco giratorio se resuelven en el marco estacionario. A medida que avanza la solución, se realiza una transferencia constante de información en la interfaz MRF. Mientras que la solución del campo de flujo en el marco giratorio en la región que rodea el impulsor imparte la rotación del impulsor a la región fuera de este marco, el impulsor en sí no se mueve durante este tipo de cálculo. Su posición es estática. Si el impulsor se monta en un eje central en un tanque con deflector, esto significa que la orientación de las palas del impulsor en relación con los deflectores no cambia durante la solución. Si la interacción entre el impulsor y los deflectores es débil, la orientación relativa del impulsor y los deflectores no importa. Sin embargo, si la interacción es fuerte, la solución con el impulsor en una posición con respecto a los deflectores será diferente de la del impulsor en una posición diferente. Por lo tanto, el modelo se recomienda para simulaciones en las que la interacción impulsor-deflector es débil (De La Concha-Gómez et al., 2019). 


\subsection{Antecedentes}

En la literatura es una práctica común evaluar la eficiencia de mezclado de diferentes tipos de impulsores comparando parámetros de macro mezclado como número de bombeo, número de potencia, o la relación entre ellos (Nienow, 1996; Cheng et al., 2013; Ramírez-Muñoz et al., 2017; Márquez-Baños et al., 2019).

Una de las partes importantes de los sistemas de agitación son los impulsores que se pueden definir como máquinas que mueven fluidos al igual que las bombas. Haciendo esta analogía, se puede calcular la eficiencia que es la relación entre energía cinética del fluido que fluye y la entrada de energía mecánica del impulsor. Para poder realizar estos cálculos son utilizados los parámetros de macro mezclado descritos previamente (Grenville and Giacomelli, 2017).

Nienow et. al (1996) reportaron parámetros de macro mezclado de varios impulsores, entre ellos el PBT4 y el HE3. En la Tabla 2.1, se comparan estos valores con los de la Turbina Rusthon (Paul et al. 2004) en el régimen turbulento. De acuerdo a los valores mostrados de estos parámetros el impulsor HE3 resulta ser el más eficiente ya que tiene la mayor efectividad de mezclado. Esta relación es un parámetro que se puede entender como el bombeo que se genera por unidad de potencia consumida en un sistema agitado por lo que entre mayor sea su magnitud mayor será la eficiencia de mezclado. En los sistemas limitados por bombeo como son los sistemas con agitadores de flujo axial se busca que este parámetro sea mayor.

Tabla 2.1 Valores de parámetros de mezclado de tres impulsores.

\begin{tabular}{ccccc}
\hline Impulsor & $\mathbf{D} / \mathbf{T}$ & $\mathbf{N}_{\mathbf{P}}$ & $\mathbf{N}_{\mathbf{Q}}$ & $\mathbf{N}_{\mathbf{Q}} / \mathbf{N}_{\mathbf{P}}$ \\
\hline Rushton & 0.333 & 5 & 0.74 & 0.15 \\
PBT4 & 0.333 & 1.7 & 0.73 & 0.43 \\
HE3 & 0.46 & 0.305 & 0.41 & 1.34 \\
\hline
\end{tabular}

Los tanques agitados se usan ampliamente en la industria química y la dinámica de fluidos computacional (CFD) resulta ser una herramienta para determinar información 
detallada sobre la hidrodinámica de algún fluido en estudio que es necesaria para modelar procesos subsecuentes en tanques agitados.

Los modelos de CFD son capaces de predecir las características de los fluidos de manera razonable, dependerá de los datos que se requieren extraer para definir la resolución de la malla ya que, por ejemplo, el campo de flujo y la velocidad media no están relacionadas directamente con la resolución de la malla. Si lo que se busca es modelar un sistema agitado para extraer datos de velocidad y campo de flujo, una malla con resolución baja o número de elementos pequeño es suficiente. En cambio si lo que se necesita es la predicción de número de potencia y de energía cinética turbulenta la resolución de la malla deberá ser mayor debido a que en tanto mayor número de elementos se tenga en el sistema a modelar, mayor será la precisión. Para lograr un modelado correcto se debe tener un balance entre precisión y tiempo/costo de computo (Deglon and Meyer, 2006).

Existe un efecto importante relacionado a la geometría y ubicación de los impulsores de paletas inclinadas que generan un flujo axial. En el caso cuando el impulsor esté más lejano al fondo del tanque, el NP disminuye. Con este tipo de impulsores, se puede generar un flujo de bombeo hacia donde en esta región se genera una alta turbulencia. Si el impulsor está colocado cerca del fondo del tanque las velocidades de flujo se limitan por las paredes del fondo del tanque. A una altura determinada el $N_{P}$ permanece constante, en el caso del PBT4 sucede cuando h/T>1/3 en un rango de número de Reynolds turbulento (Beshay et al., 2001).

En tanques agitados mecánicamente, la elección del recipiente y la geometría del impulsor, el número y tipo de deflectores pueden variar según la operación realizada. Específicamente la selección de deflectores puede beneficiar la homogeneización del fluido que se pretende mezclar. Si no se colocan deflectores en la mezcla de un fluido de baja viscosidad el impulsor imparte un movimiento tangencial al líquido al momento de girar, en este caso el fluido se mueve a lo largo a alta velocidad en trayectorias circulares con una mezcla pobre y se forma un vórtice en la superficie libre, cuya profundidad depende de la velocidad de giro del impulsor. En un tanque agitado con deflectores se obtienen ventajas de mezclado como son la eliminación del vórtice y se obtienen flujos axiales mucho más fuertes, lo que lleva a una mejor velocidad de mezcla. El mejor ángulo de inclinación de los 
deflectores es de $70^{\circ}$. En este estudio se optó por colocarlos a $90^{\circ}$ por conveniencia industrial ya que son los más utilizados y están ya instalados dentro de Axalta (Kamla et al., 2017).

Dentro de la búsqueda de estudios con aplicación industrial para fluidos no newtonianos son muy pocos y con aplicación en recubrimientos es prácticamente nulo.

\subsection{Justificación}

En la literatura existen muy pocos trabajos con aplicación industrial en la fabricación de recubrimientos, por lo que uno de los factores de mayor relevancia de este trabajo es llevar el conocimiento que existe hoy en día a un nivel de aplicación real con el cual la industria de los recubrimientos base agua que, en México es creciente (AMAIA, 2018) se pueda ver beneficiado con el análisis que se realizará para obtener una propuesta de ahorro económico únicamente modificando la agitación en la manufactura de un recubrimiento blanco.

La problemática actual consiste en que durante la manufactura de recubrimientos para la industria automotriz en la fábrica de Axalta se presentan detractores debido a una baja homogeneización en los tanques agitados disponibles que alargan el tiempo de ciclo o de proceso debido a retrabajos o acondicionamientos adicionales.

Aunado a lo anterior, el conocimiento de la hidrodinámica de las diferentes configuraciones de los tanques disponibles es mínimo lo que complica una buena toma de decisiones durante la manufactura de los recubrimientos. Siendo necesaria una compresión adecuada de los fenómenos que ocurren en los sistemas de mezclado empleados en estos procesos.

En este trabajo se estudiará la hidrodinámica de una configuración de tanque instalado y otros dos con dimensiones y geometrías estándar para la manufactura de recubrimientos de la industria automotriz mediante el estudio reológico de un recubrimiento blanco base agua. Esto con la finalidad de establecer las condiciones de operación que resulten con un menor consumo de potencia y un menor tiempo de proceso. 


\section{HIPÓTESIS Y OBJETIVOS}

3.1 Hipótesis

$\checkmark$ Es posible mejorar la eficiencia de mezclado en la fabricación de un recubrimiento blanco encontrando las condiciones de operación y geometrías adecuadas de los tanques de mezclado ya instalados en una planta de fabricación de recubrimientos.

\subsection{Objetivo general}

$\checkmark$ Caracterizar hidrodinámicamente tres diferentes impulsores en tanques agitados a escala laboratorio empleados en la producción de un recubrimiento blanco mediante mediciones experimentales y simulaciones numéricas.

\subsection{Objetivos particulares}

$\checkmark$ Caracterizar reológicamente el fluido de interés (recubrimiento blanco y fluidos modelo que pueden representar su comportamiento).

$\checkmark$ Realizar simulaciones CFD de los sistemas a analizar y validar los resultados de las simulaciones usando mediciones experimentales de potencia.

$\checkmark$ Analizar el efecto de la reología y de la configuración del sistema de mezclado sobre las variables hidrodinámicas de interés: tasa de corte, disipación de energía, curva de bombeo y de potencia y la relación entre ellas. 


\section{MATERIALES Y MÉTODOS}

Como caso de estudio se analizaron dos impulsores axiales de cuatro y seis paletas inclinadas y un impulsor de alta eficiencia a escala laboratorio bajo condiciones de similitud geométrica de un tanque de agitado instalado en planta. Las relaciones geométricas que conservadas en el sistema de mezclado de escala laboratorio y de planta fueron: D/T, Z/T y C/T.

Este trabajo se centró en el estudio de un recubrimiento blanco manufacturado por Axalta, el cual fue primero caracterizado reológicamente con ayuda de un reómetro Anton Paar MCR 301. Una vez conocida la reología del material en estudio y parámetros de operación de las tres configuraciones del sistema de mezclado, se realizaron simulaciones mediante técnicas de Dinámica de Fluidos Computacional. Dichas simulaciones fueron validadas experimentalmente mediante mediciones de potencia obtenidas mediante mediciones de torque.

Se evaluó la eficiencia de los tres impulsores de estudio mediante la medición del corte y la comparación de $\mathrm{N}_{\mathrm{Q}} / \mathrm{N}_{\mathrm{P}}$ de cada sistema agitación y así se definió cuál es el mejor impulsor de los tres para la fabricación de recubrimiento blanco.

\subsection{Equipo experimental}

El sistema de mezclado estudiado se compone de un tanque de acero inoxidable enchaquetado y equipado con cuatro deflectores igualmente espaciados con un ancho de 1 $\mathrm{cm}$ y grosor de $1 \mathrm{~mm}$, el tanque tiene fondo torisférico y con diámetro interno de T=165 mm. El volumen del fluido de trabajo durante todos los experimentos fue de $3.8 \mathrm{~L}$. La agitación fue provista mediante un equipo de agitación Dispermat ${ }^{\circledR}$ AE01, el cual cuenta con una potencia nominal de $0.75 \mathrm{HP}$ y rota en sentido de las manecillas del reloj en un intervalo de operación entre 30 y 10,000 RPM.

Las relaciones geométricas adimensionales correspondientes a la distancia del fondo del tanque al centro del impulsor (C), altura de líquido en reposo $(\mathrm{Z})$ y diámetro del impulsor que se usaron se presentan en la Tabla 4.1 
Tabla 4.1. Relaciones geométricas adimensionales de las configuraciones analizadas

\begin{tabular}{cccc}
\hline Impulsor & $\mathrm{C} / \mathrm{T}$ & $\mathrm{Z} / \mathrm{T}$ & $\mathrm{D} / \mathrm{T}$ \\
\hline PBT4 & 0.39 & 1 & 0.38 \\
PBT6 & 0.11 & 1 & 0.32 \\
HE3 & 0.39 & 1 & 0.38 \\
\hline
\end{tabular}

Para las mediciones de torque, se acopló un medidor de torque dinámico Futek® TRH300-FSH1980 al eje de rotación. Este instrumento permite mediciones de torque dinámico de hasta 3,000 RPM, tiene una capacidad máxima de $6 \mathrm{~N} \cdot \mathrm{m}$ y una resolución de 6 $\mathrm{mN} \cdot \mathrm{m}$, mientras que cuenta con una precisión del $0.5 \%$ en toda la escala de su intervalo de medición.

Las mediciones de torque fueron obtenidas en tiempo real mediante un transductor Andilog ${ }^{\circledR}$ modelo CNR-EA-TRD6 y enviadas a una computadora en la que fueron procesadas mediante el software Caligraph ${ }^{\circledR}$ versión 1.3.0. El arreglo experimental antes mencionado se presenta a detalle en el esquema mostrado en la Figura 4.1.

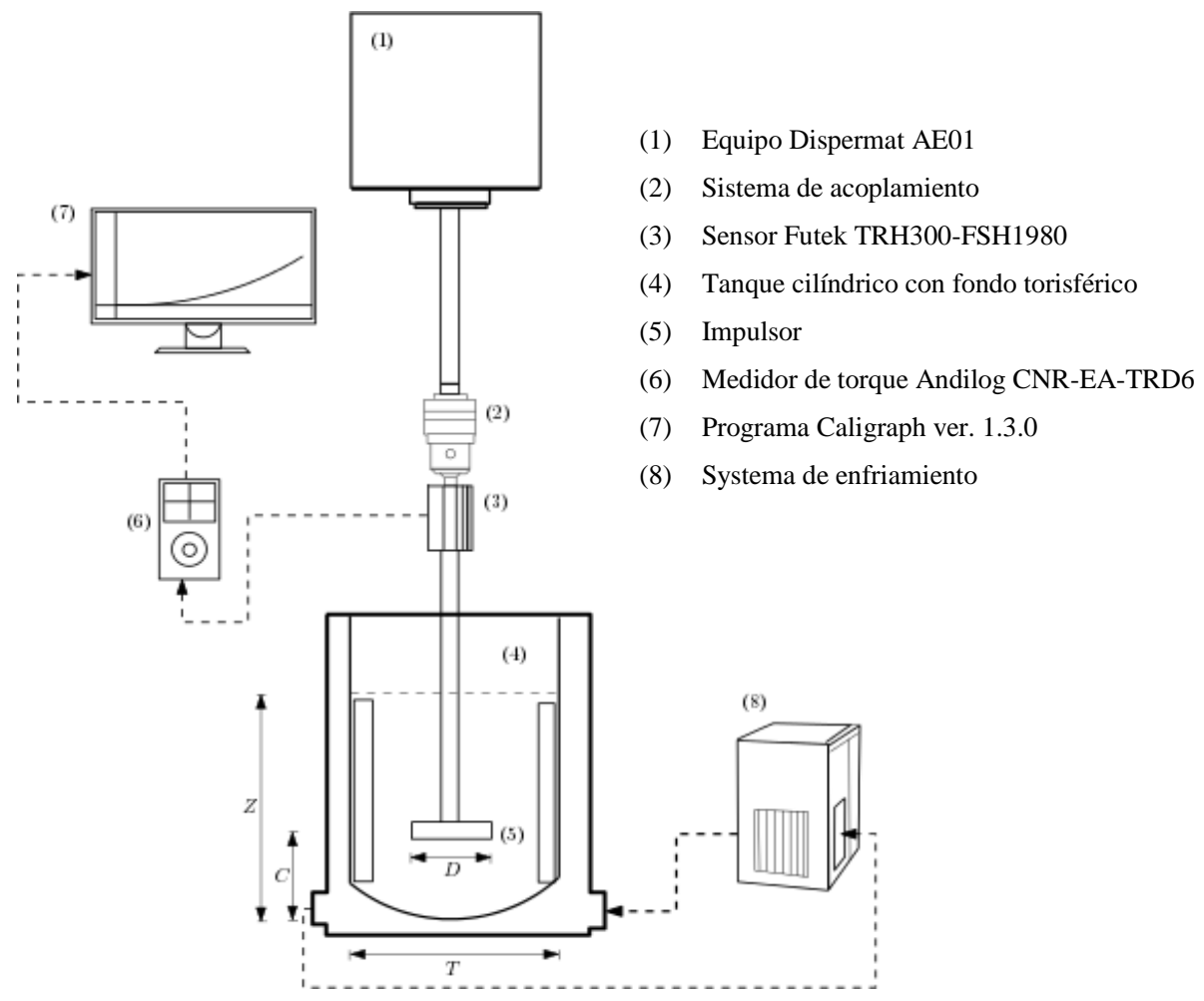

Figura 4.1. Esquema del arreglo experimental. 
En cada medición experimental se almacenaron veinte mediciones de torque por segundo durante $60 \mathrm{~s}$, y el valor promedio del torque $(\mathfrak{I})$ se usó para calcular la potencia mecánica suministrada al fluido mediante la ecuación (4.1):

$$
P=2 \pi N \mathfrak{J}
$$

La temperatura de trabajo del fluido de trabajo se fijó a $25^{\circ} \mathrm{C}$ y se controló circulando un fluido de enfriamiento/calentamiento a través de la chaqueta del tanque, la cual se acopló a un baño de enfriamiento/calientamiento marca Scorpion Scientific, modelo A20300 de 11 L de capacidad.

Los impulsores que se utilizaron para el desarrollo de este trabajo fueron tres: un impulsor de cuatro paletas planas inclinadas a $45^{\circ}$ (PBT4), un impulsor de seis paletas planas inclinadas a $35^{\circ}$ (PBT6) y un impulsor de alta eficiente de 3 paletas (HE3). El impulsor PBT6 fue construido mediante impresión 3D usando ácido poliláctico (PLA, por sus siglas en inglés), mientras que los impulsores PBT4 y HE3 fueron elaborados en acero inoxidable. Las dimensiones de cada uno de ellos se presentan en la Figura 4.2. El tipo de material con el que se construyeron los impulsores no tiene algún efecto en las mediciones de torque ya que el equipo tiene la opción de tara. La rugosidad de los impulsores impresos es baja ya que se imprimieron con la calidad más alta y aunque sigue estando presente la rugosidad, el arrastre presente en el experimento es mayor por forma que por superfice, por lo que se puede despreciar. 
PBT4
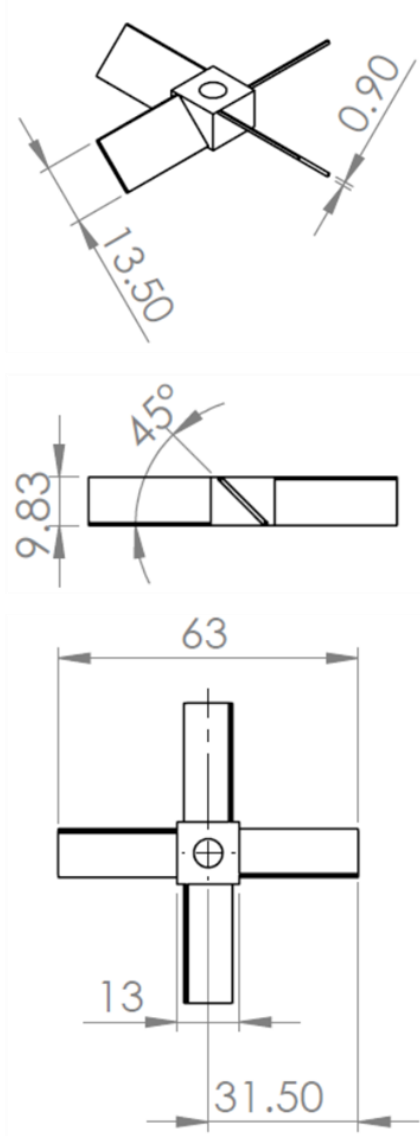

PBT6
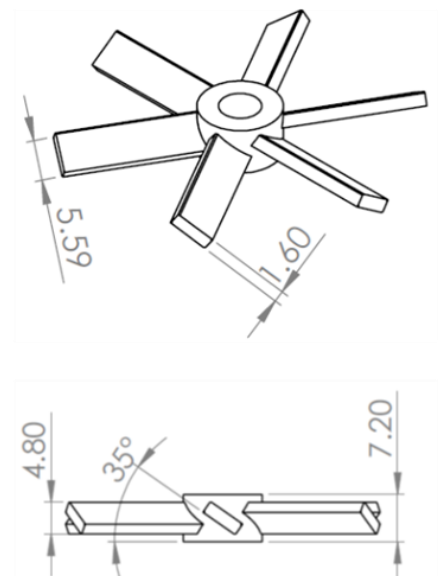

52

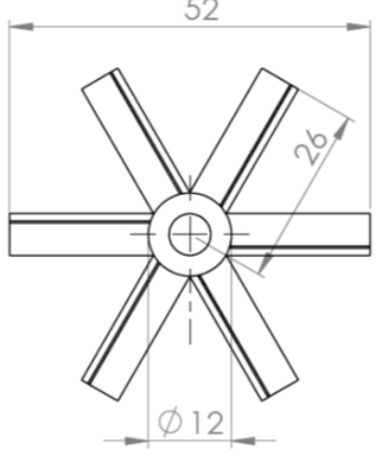

HE3
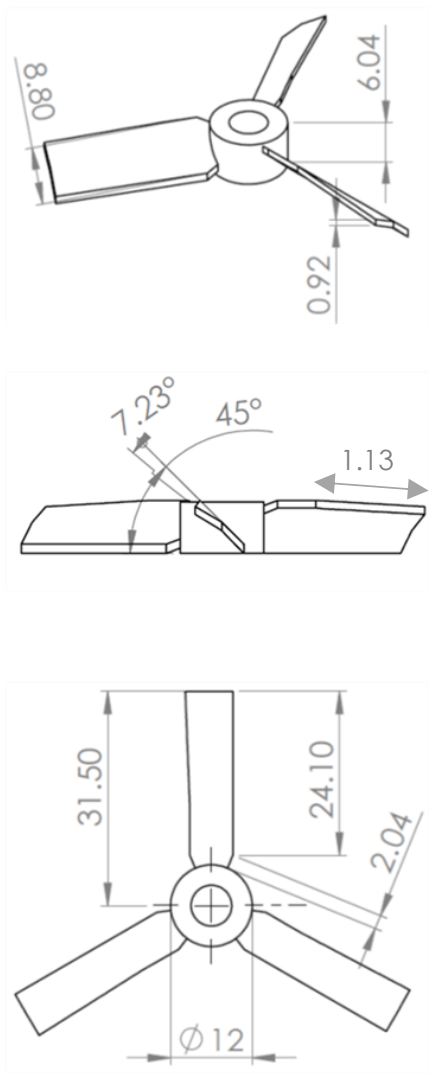

Figura 4.2. Dimensiones de impulsores PBT4, PBT6 y HE3 en mm.

\subsection{Caracterización de fluido de trabajo}

Como fluidos de trabajo se utilizó agua potable y el recubrimiento blanco Axalta. Las propiedades (densidad y viscosidad) del agua de $25^{\circ}$ fueron tomadas de la literatura (Crane, 1988). La densidad el recubrimiento blanco midió mediante un gravimétrico empleando un probeta graduada, obtenido un valor de $1157 \mathrm{~kg} / \mathrm{m}^{3}$, mientras que su reología se caracterizó en un reómetro Anton Paar MCR 301 empleando la geometría de platos a una temperatura constante de $25^{\circ} \mathrm{C}$ con un intervalo de corte de 0.01 a $3000 \mathrm{~s}^{-1}$. 
De la curva de flujo obtenida se ajustaron los datos experimentales al modelo de ley de potencia. Los parámetros obtenidos a este modelo fueron $m=6.3929 \mathrm{~Pa} \cdot \mathrm{s}^{\mathrm{n}}$ y $n=0.3704$, con un coeficiente de correlación de $\mathrm{R}^{2}=0.996$ que demuestra un ajuste muy cercano a los datos experimentales, correspondiendo al intervalo de tasa de corte de 0.0345 a $4132 \mathrm{~s}^{-1}$. De acuerdo al valor obtenido de $n$ el fluido se considera adelgazante, lo cual corresponde al comportamiento de los recubrimientos en la industria. El resultado de este ajuste se muestra en la Figura 4.3, el intervalo de ajuste del modelo para los parámetros reológicos se definió mediante simulaciones preliminares del sistema a la máxima velocidad analizada.

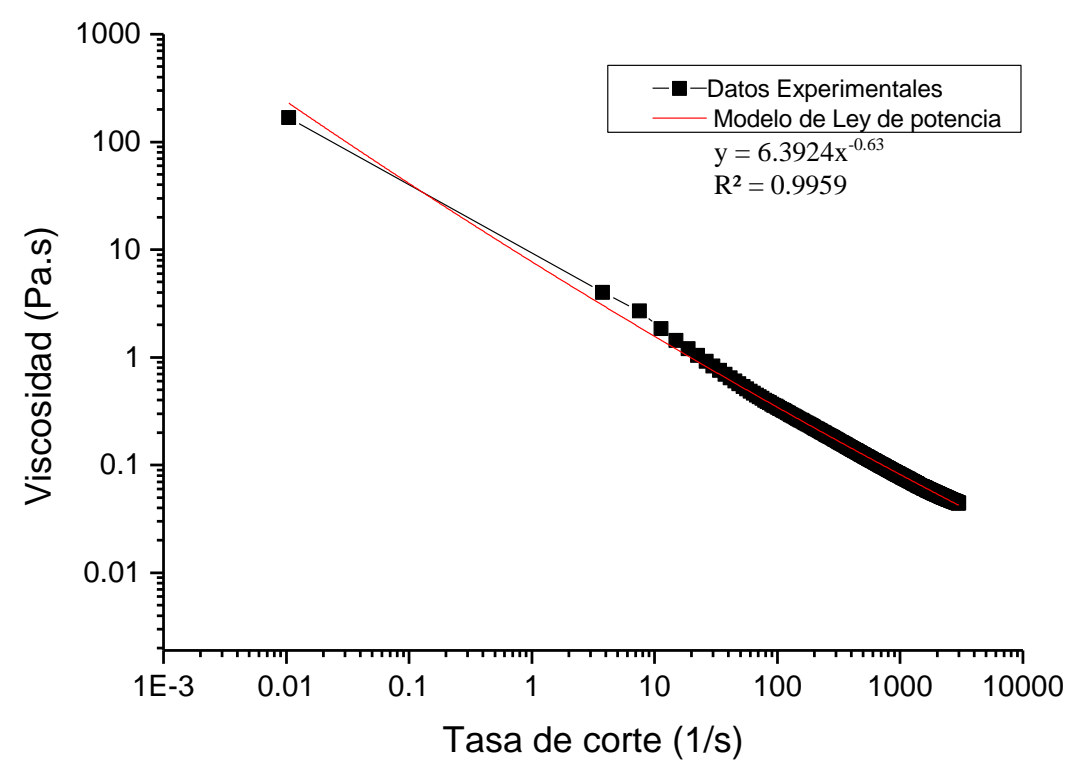

Figura 4.3. Curva reológica de recubrimiento blanco.

\subsection{Metodología Numérica}

\subsubsection{Generación de la geometría y malla computacional}

El sistema de mezclado se digitalizó empleando el módulo Ansys®-Design Modeler. Una vez extraído el dominio de flujo, se construyó la malla computacional usando el módulo Ansys®-Meshing estableciéndose el origen del sistema de coordenadas cartesianas en el centro de los impulsores. Se definió una serie de volúmenes de estudio alrededor de los 
impulsores en los que se respetó la relación recomendada (Márquez-Baños et al., 2019) en la Tabla 4.2

Tabla 4.2. Relación de volúmenes alrededor del impulsor

\begin{tabular}{ccc}
\hline Volumen & $\mathrm{h} / \mathrm{H}$ & $\mathrm{r} / \mathrm{R}$ \\
\hline $\mathrm{VC}$ & 1 & 1 \\
$\mathrm{~V} 1$ & 1.5 & 1.075 \\
$\mathrm{~V} 2$ & 2 & 1.15 \\
$\mathrm{~V} 3$ & 2.5 & 1.225 \\
$\mathrm{~V} 4$ & 3 & 1.3 \\
$\mathrm{~V} 5$ & 3.5 & 1.375 \\
$\mathrm{~V} 6$ & 4 & 1.45 \\
$\mathrm{~V} 7$ & 4.5 & 1.525 \\
$\mathrm{~V} 8$ & 5 & 1.6 \\
\hline
\end{tabular}

En el volumen restante no se realizó segmentación en la malla computacional y este volumen restante se denominó VR. Esta segmentación se realizó para los impulsores PBT4 y HE3, mientras que el impulsor PBT6 no fue posible elaborar todos estos volúmenes debido a la complejidad de la malla. Debido a esto solo se generaron cinco volúmenes tomando las dimensiones de los volúmenes pares (i.e. VC, V2, V4, V6, V8). Los detalles de la malla computacional segmentada se presentan en la Figura 4.4. 


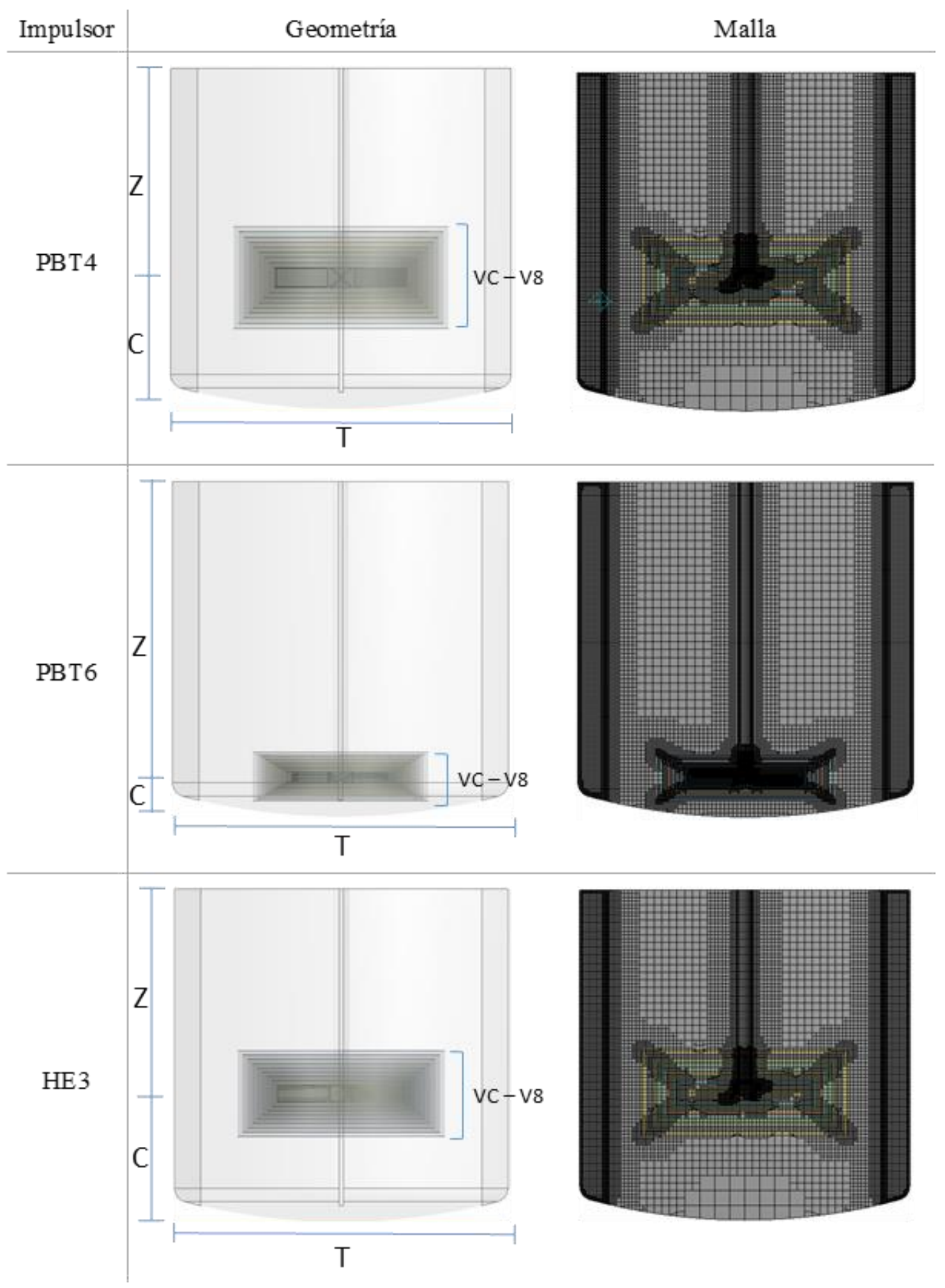

Figura 4.4. Sistema de mezclado y su malla computacional segmentada en los volúmenes de análisis. Los valores usados de $\mathrm{C}, \mathrm{Z}$ y $\mathrm{T}$ son acordes a la Tabla 4.1. 
El método de malleo utilizado en las configuraciones para el estudio de este trabajo fue Cutcells, el cual nos permite generar una mayor cantidad de elementos tipo hexaédricos de manera automática.

La malla generada en cada uno de los sistemas evaluados tiene una estructura conforme, lo cual significa que los límites de cada una de las celdas generadas coinciden entre ellas y, por lo tanto, no se requiere una interpolación entre regiones adyacentes. La calidad de la malla se aseguró manteniendo una oblicuidad máxima para todas las mallas evaluadas por debajo de 0.9 .

\subsubsection{Solución de ecuaciones gobernantes}

El modelo que describe el movimiento del fluido para resolver el dominio computacional se define en el módulo de Fluent y se tomaron las siguientes consideraciones:

- Régimen de flujo turbulento

- Condiciones isotérmicas

- Estado estacionario

- Flujo incompresible

- La superficie libre no genera vórtice

- Rotación del fluido en sentido contrario de las manecillas del reloj

\section{Especificación de los modelos de flujo}

El modelo de turbulencia utilizado para las simulaciones fue el $k-\varepsilon$ estándar con funciones estándar para el tratamiento cerca de las paredes sólidas.

\section{Especificación de los materiales}

En la Tabla 4.3 se muestra la especificación de los materiales utilizados y los coeficientes del modelo reológico ley de potencia determinados experimentalmente: 
Tabla 4.3. Propiedades especificadas en Fluent.

\begin{tabular}{cccc}
\hline Propiedad & Unidades & Agua & Recubrimiento blanco \\
\hline Densidad & $\mathrm{kg} / \mathrm{m}^{3}$ & 998.2 & 1154.0 \\
Viscosidad & $\mathrm{kg} /(\mathrm{m} \cdot \mathrm{s})$ & $1.00 \mathrm{E}-03$ & - \\
Índice de consistencia & $\mathrm{kg} /(\mathrm{m} \cdot \mathrm{s})^{\mathrm{n}}$ & - & 6.3929 \\
Índice de adelgazamiento al flujo & - & - & 0.3704 \\
\hline
\end{tabular}

\section{Especificación de las condiciones frontera}

La región de rotación se estableció en los volúmenes definidos alrededor del impulsor. En las paredes del impulsor y la flecha se implantó una condición de rotación. Las paredes del tanque y los deflectores se mantuvieron estáticas asignando la condición de no deslizamiento. Finalmente la superficie del líquido se definió con un esfuerzo de corte cero, es decir, se despreció la transferencia de momento entre el líquido y el aire.

Especificación de los métodos de solución y convergencia

La solución que se obtiene mediante Fluent Ansys 17.1 es mediante un proceso iterativo, en este caso el método de solución utilizado fue un algoritmo acoplado presión-velocidad, una discretización tipo QUICK para los términos de velocidad y PRESTO! para los términos de presión. En la aproximación de gradiente se utilizó mínimos cuadrados basados en celdas. El criterio de convergencia en los residuales fue por un valor por debajo de $10^{-5}$.

Análisis de independencia de malla y validación de los resultados numéricos

El análisis de independencia de malla, la selección de la malla más adecuada y su validación consiste en comparar los resultados numéricos obtenidos de la simulación de los parámetros hidrodinámicos de interés a medida que se incrementa el número de elementos de la malla, y éstos a su vez se comparan con mediciones experimentales 
propias o con datos reportados en la literatura. La malla se considera independiente cuando la variación del parámetro analizado cambia muy poco (alrededor del 3\%) con respecto a la malla más densa.

\subsubsection{Postprocesamiento de los datos}

Una vez obtenido el campo de flujo a partir de la solución numérica del modelo, se pueden graficar variables de interés como los perfiles de presión, componentes de la velocidad, tasa de corte, viscosidad, torque y otras variables locales. En este proyecto, a partir del torque numérico se calculó la potencia suministrada por el agitador $\left(P_{i n}\right)$ al fluido usando la ecuación (4.1).

El bombeo inducido por cada impulsor axial evaluado se calculó a partir del campo de velocidad numérico mediante la ecuación (2.10), esto con el fin hacer una comparación entre los tres impulsores para cada uno de los fluidos evaluados. 


\section{ANÁLISIS Y DISCUSIÓN DE RESULTADOS}

5.1 Análisis de independencia de malla

Para garantizar que los resultados numéricos sean independientes del número de elementos en la malla se construyeron cuatro mallas por cada sistema de agitación evaluado, cada una con diferente número de elementos. Con el incremento del número de elementos de cada malla la malla más densa se incrementaba aproximadamente al doble para cada volumen definido en cada malla computacional, como se presenta en las Tablas 5.1 a 5.3. Para el impulsor PBT4 y HE3 se generaron 8 volúmenes alrededor del impulsor y para el impulsor PBT6 se generaron únicamente 4 volúmenes alrededor del impulsor.

Tabla 5.1. Número de elementos por volumen de cada malla para el impulsor PBT4.

\begin{tabular}{crrrr}
\hline Volumen & \multicolumn{1}{c}{ Malla 1 } & \multicolumn{1}{c}{ Malla 2 } & \multicolumn{1}{c}{ Malla 3 } & \multicolumn{1}{c}{ Malla 4 } \\
\hline VC & 295,406 & 722,055 & $2,089,676$ & $4,226,673$ \\
V1 & 336,537 & 759,941 & $2,446,857$ & $4,654,152$ \\
V2 & 53,001 & 168,861 & 419,262 & 931,668 \\
V3 & 44,376 & 139,051 & 250,778 & 628,393 \\
V4 & 42,624 & 78,035 & 148,905 & 290,138 \\
V5 & 34,914 & 54,332 & 104,389 & 174,095 \\
V6 & 44,356 & 83,934 & 151,827 & 265,766 \\
V7 & 52,175 & 99,607 & 157,987 & 252,368 \\
V8 & 41,792 & 88,352 & 200,893 & 327,001 \\
VR & 581,344 & $1,476,098$ & $2,471,813$ & $4,395,954$ \\
Dominio & $1,526,525$ & $3,670,266$ & $8,442,387$ & $16,146,208$ \\
Completo & & & & \\
\hline
\end{tabular}


Tabla 5.2. Número de elementos por volumen de cada malla para el impulsor PBT6.

\begin{tabular}{crrrr}
\hline Volumen & \multicolumn{1}{c}{ Malla 1 } & \multicolumn{1}{c}{ Malla 2 } & \multicolumn{1}{c}{ Malla 3 } & \multicolumn{1}{c}{ Malla 4 } \\
\hline VC & 312,129 & 780,416 & $1,729,794$ & $2,996,035$ \\
V2 & 454,275 & $1,014,140$ & $2,358,951$ & $4,860,881$ \\
V4 & 57,595 & 90,910 & 154,696 & 334,956 \\
V6 & 26,228 & 51,126 & 117,696 & 252,994 \\
V8 & 15,326 & 49,339 & 83,058 & 138,764 \\
VR & 519,096 & $1,223,362$ & $2,251,427$ & $3,839,408$ \\
Dominio & $1,384,639$ & $3,209,293$ & $6,695,622$ & $12,423,038$ \\
Completo & & & & \\
\hline
\end{tabular}

Tabla 5.3. Número de elementos por volumen de cada malla para el impulsor HE3.

\begin{tabular}{crrrr}
\hline Volumen & \multicolumn{1}{c}{ Malla 1 } & Malla 2 & \multicolumn{1}{c}{ Malla 3 } & \multicolumn{1}{c}{ Malla 4 } \\
\hline VC & 127,294 & 435,220 & $1,218,925$ & $2,373,620$ \\
V1 & 69,269 & 227,814 & 580,216 & $1,100,559$ \\
V2 & 34,612 & 74,995 & 170,489 & 310,780 \\
V3 & 36,672 & 66,312 & 126,925 & 248,895 \\
V4 & 44,118 & 110,709 & 230,430 & 563,840 \\
V5 & 35,483 & 59,626 & 111,825 & 390,313 \\
V6 & 39,112 & 58,614 & 93,425 & 375,273 \\
V7 & 41,350 & 77,764 & 140,400 & 416,956 \\
V8 & 52,335 & 127,767 & 275,775 & 565,211 \\
VR & 596,047 & $1,024,349$ & $1,771,419$ & $3,407,736$ \\
Dominio & $1,076,292$ & $2,263,170$ & $4,719,829$ & $9,753,183$ \\
Completo & & & & \\
\hline
\end{tabular}

Para determinar la malla que es independiente del número de elementos, se realizaron simulaciones numéricas para estas cuatro mallas usando el fluido newtoniano al mayor número de Reynolds evaluado en este estudio $(\mathrm{Re}=66,000)$. A partir de los resultados de las simulaciones de las cuatro mallas se extrajeron los valores de potencia y de la tasa de corte local y promedio en los diferentes volúmenes, siguiendo los criterios definidos en trabajos de la literatura (Ramírez-Gómez et al., 2015; Ramírez-Muñoz et al., 2017; Márquez-Baños et al., 2019).

La independencia de malla se aseguró al comparar los valores de tasa de corte tanto locales de un perfil radial como promedio por volumen y velocidad local de un perfil radial para dos tamaños de malla consecutivos. Si la diferencia entre ellos era inferior al 5\%, la 
solución numérica basada en la malla con el menor número de elementos se consideraba independiente del número de elementos de la malla. En la Figura 5.1 se muestran los resultados de la tasa de corte promedio, en las Figuras 5.2 y 5.3 se muestra los perfiles locales en un perfil radial de la tasa corte y velocidad respectivamente en línea de corte desde la punta del impulsor al bafle para los 3 impulsores PBT4, HE3 y PBT6.

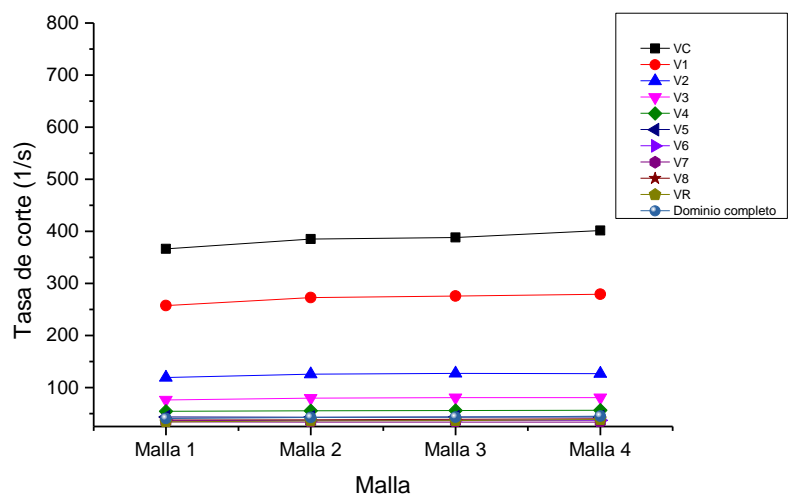

a)

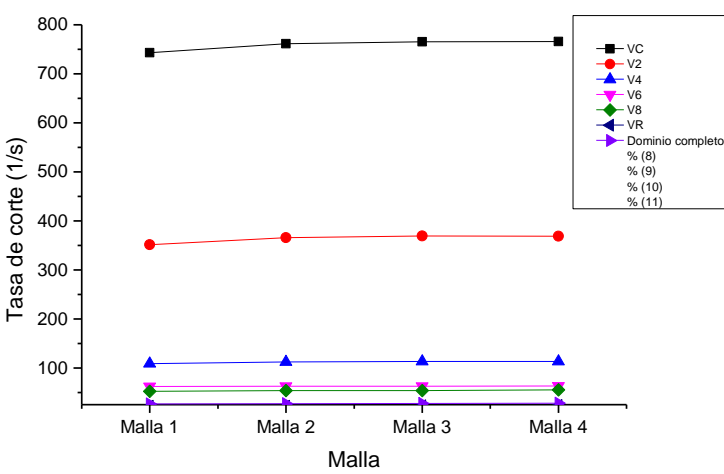

b)

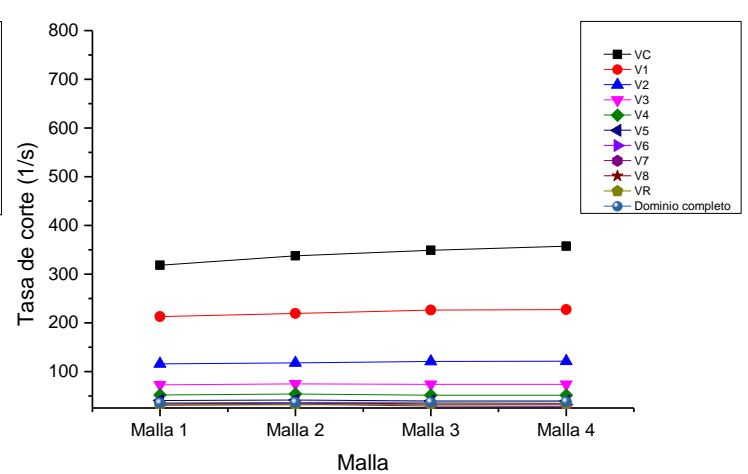

c)

Figura 5.1. Tasa de corte promedio de los impulsores a) PBT4, b) PBT6 y c) HE3 para análisis de independencia de malla con fluido newtoniano. 


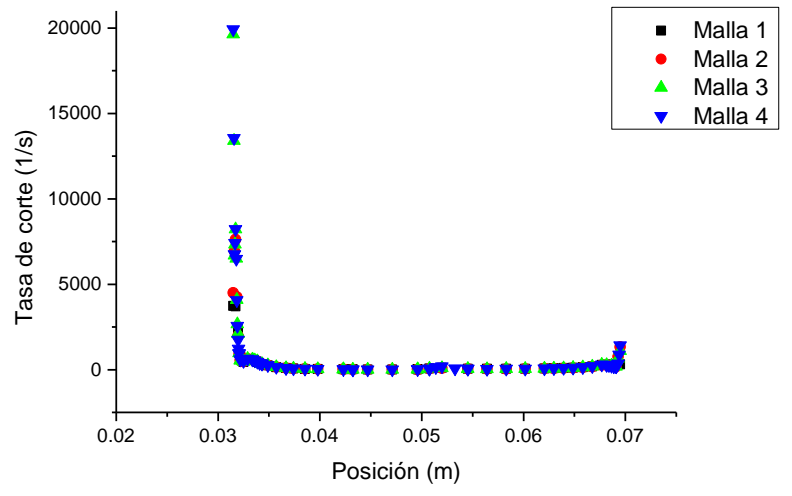

a)

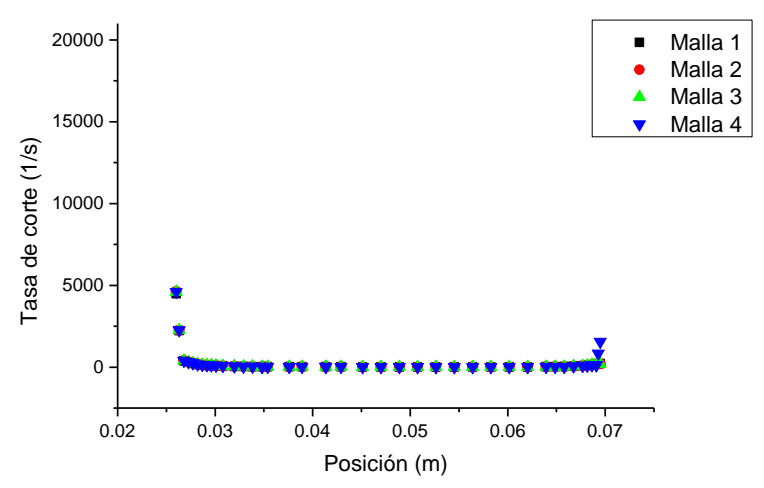

b)

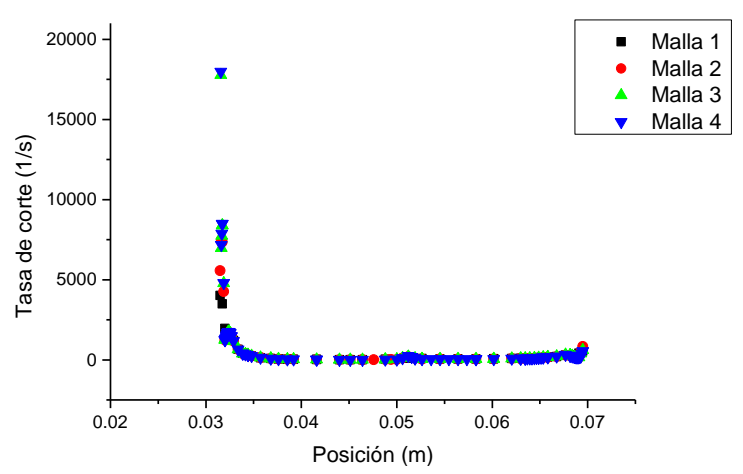

c)

Figura 5.2. Tasa de corte local de un perfil radial de los impulsores a) PBT4, b) PBT6 y c) HE3 para análisis de independencia de malla con fluido newtoniano. 


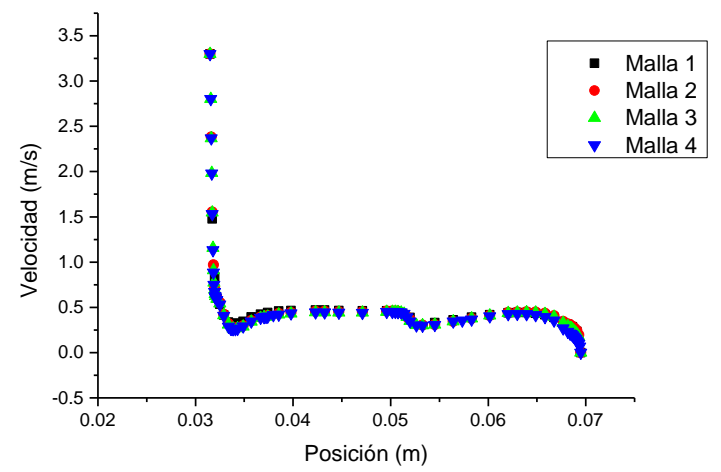

a)

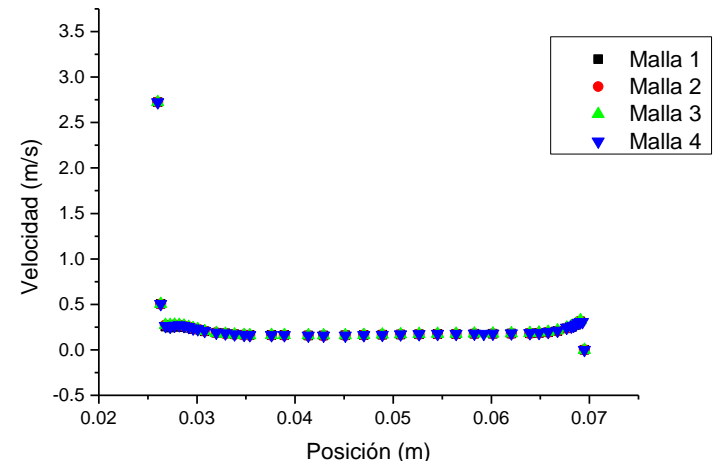

b)

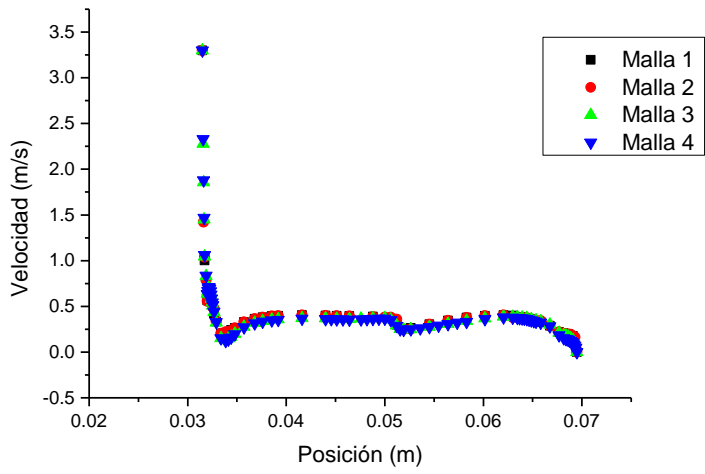

c)

Figura 5.3. Velocidad local de un perfil radial para el impulsor a) PBT4, b) PBT6 y c) HE3 para análisis de independencia de malla con fluido newtoniano. 
En la Figura 5.1 se puede notar que los volúmenes definidos más alejados del impulsor (de V6 a V8) alcanzan la independencia de malla respecto al valor de la tasa de corte promedio en mallas menos densas, es decir, con un menor número elementos. Sin embargo para los volúmenes definidos cercanos al impulsor (VC a V2) se distingue que esta independencia se logra en la malla 2. Por esta razón la malla 2 fue la seleccionada, este malla cumple con el criterio previamente establecido de independencia.

Para el perfil radial mostrado en la Figura 5.2 se puede notar que el valor máximo en la punta del impulsor solo puede ser alcanzado con mallas más densas, notándose que valores de las mallas 3 y 4 se sobreponen, mientras las mallas inferiores predicen valores menores y con diferencias mayores al 5\% en esta región. Por otro lado los valores del perfil de velocidad mostrados en la Figura 5.3 muestran que para esta variable la independencia de malla se alcanza en la malla 2, notándose que en la punta el impulsor se predice el mismo valor máximo de la velocidad y coincidiendo también en el resto del perfil radial.

Debido a que en el presente estudio el análisis de los valores locales máximos de la tasa de corte no son de interés y que el número de elementos para llegar a predecir este valor en la punta impulsor es muy elevado (mayor a 6 millones), se decidió definir como mallas independientes para cada impulsor las siguientes mallas para cada impulsor:

Tabla 5.4. Malla independiente por impulsor y número de elementos.

\begin{tabular}{ccc}
\hline Impulsor & Malla independiente & Número de elementos \\
\hline PBT4 & 2 & $3,670,266$ \\
PBT6 & 2 & $3,209,293$ \\
HE3 & 3 & $4,719,829$ \\
\hline
\end{tabular}

Del análisis anterior, todas las simulaciones realizadas para comparar el desempeño de los impulsores se llevaron a cabo con las mallas mostradas en la Tabla 5.4. 


\subsection{Análisis de la potencia consumida}

Con la finalidad de validar los resultados numéricos obtenidos de los modelos computacionales de cada uno de los tres sistemas de agitación evaluados, se realizaron las simulaciones con las mallas computacionales seleccionadas tanto para el fluido newtoniano como para el no newtoniano. Para el fluido newtoniano se analizó el intervalo de número de Reynolds entre 10,000 y 66,000, de donde se extrajeron valores de N. Para el fluido no newtoniano, dado que no existe consenso en la literatura para reportar las curvas de potencia de fluidos no newtonianos adelgazantes en el régimen turbulento, los datos se presentan en forma potencia suministrada en función de la velocidad de agitación. Para este tipo de fluido, se abarcó una velocidad de agitación entre 250 y 550 RPM y se extrajeron los valores de potencia (W) a partir del torque numérico.

En la Figura 5.4 se presenta la curva de potencia ( $\mathrm{N}_{\mathrm{P}}$ vs $\mathrm{Re}$ ) en el régimen turbulento para los impulsores analizados. Se muestran los valores tanto numéricos como experimentales empleando el fluido newtoniano en donde se encontró un error máximo del 9\% para el impulsor PBT4, mientras que los otros impulsores el error máximo fue de 1\%. En esta figura se puede distinguir que el consumo de potencia es mayor en el impulsor PBT4, seguido por el PBT6 y el HE3 el consumo más bajo.

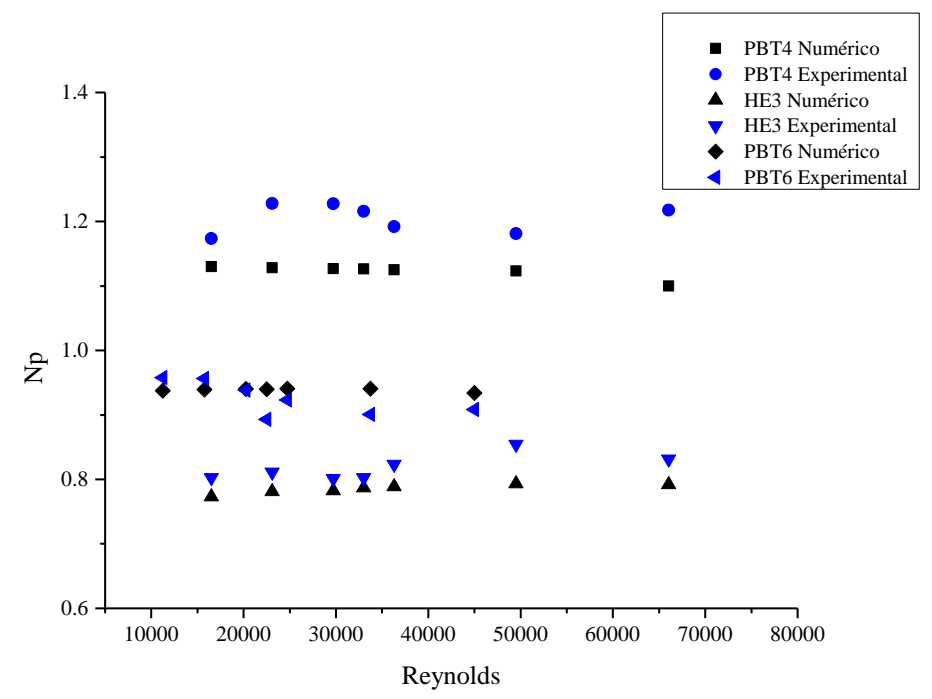

Figura 5.4. $\mathrm{N}_{\mathrm{p}}$ vs Re experimental y numérico para los impulsores PBT4, PBT6 y HE3 del fluido newtoniano. 
Comparando los resultados obtenidos contra los valores reportados en la literatura (Tabla 5.2) se observa que los valores de $\mathrm{N}_{\mathrm{P}}$ son menores debido a que las relaciones geométricas varían.

En cuanto al recubrimiento blanco (fluido no newtoniano adelgazante), en la Figura 5.5 se muestran los valores de potencia consumida por el agitador versus la velocidad de agitación (RPM). En la misma figura se incluyen los valores experimentales y numéricos. En este caso se puede observar que el valor más alto de consumo de potencia lo tiene el impulsor PBT4 y los valores más bajos se obtuvieron con el impulsor PBT6 seguido por el HE3 y el PBT6 el consumo más bajo. Comparando los valores numéricos con los datos experimentales se encontró un error máximo del $20 \%$ para el impulsor PBT4, mientras que para los otros impulsores el error máximo fue del 15\%. En todos los casos los máximos errores entre los valores numéricos y experimentales se obtuvieron para la velocidad de agitación más alta.

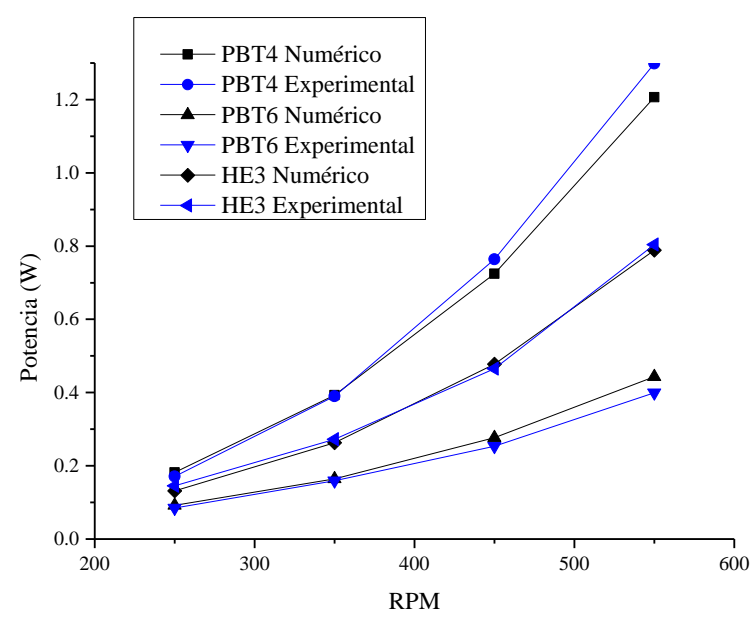

Figura 5.5. Potencia suministrado vs la velocidad de agitación (experimental y numérica) para los impulsores PBT4, PBT6 y HE3 usando el fluido no newtoniano.

\subsection{Vectores de velocidad}

En las Figuras 5.6, 5.7 y 5.8 se muestran los vectores de velocidad para el fluido newtoniano y no newtoniano que indican la dirección del flujo y los colores indican la magnitud de la velocidad. Estas figuras fueron obtenidas en un plano de corte vertical que pasa a la mitad de 
por lo menos una de las paletas alineado con dos deflectores a cuatro diferentes velocidades (250, 350, 450 y 550 RPM), lo cual se hizo para cada uno de los impulsores: PBT4 (Figura 5.6), PBT6 (Figura 5.7) y HE3 (Figura 5.8).

Las escalas de colores no son las mismas para todas las imágenes presentadas debido a que las velocidades que se presentan en cada impulsor son muy diferentes. Estos vectores son afectados por las revoluciones de giro del impulsor y cada uno de los impulsores genera más o menos velocidad por la geometría de cada uno.

Para el fluido newtoniano se puede observar que se tienen mayores velocidades y tasas de corte en todas las velocidades presentadas en comparación con el fluido no newtoniano. En todos los casos mostrados se observa un lazo de circulación, esto se presenta en los impulsores de flujo axial en régimen turbulento.

Respecto a la representación de los vectores de velocidad se observa que, en las figuras del fluido newtoniano, la distribución de colores que representa la magnitud de velocidad es más homogénea a diferencia del fluido no newtoniano donde predominan las zonas con velocidades de magnitud baja siendo en ambos casos la punta del impulsor la zona con mayor velocidad.

También se puede observar que los lazos de circulación que se generan en el fluido newtoniano son de mayor tamaño comparados con los formados en la representación del fluido no newtoniano. Para los tres impulsores evaluados, conforme se incrementa la velocidad de giro del impulsor, los lazos de circulación se hacen más grandes, lo cual sugiere que se tiene una mayor componente axial velocidad y se alcanzaría una mayor homogeneización en menor tiempo. 

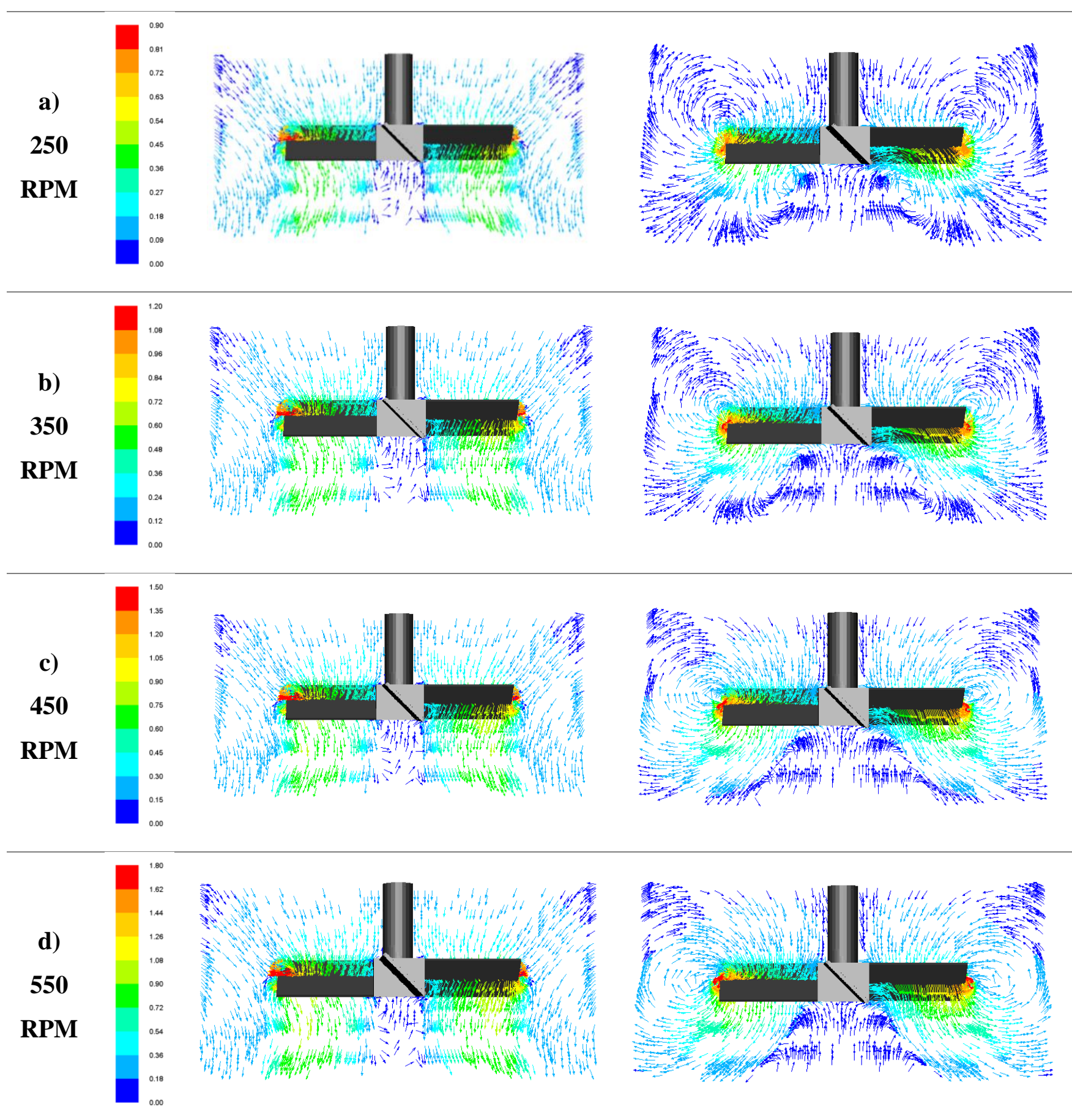

Figura 5.6. Vectores de velocidad de los fluidos newtoniano y no newtoniano a las velocidades a) 250, b) 350, c) 450 d) 550 RPM para el impulsor PBT4. 


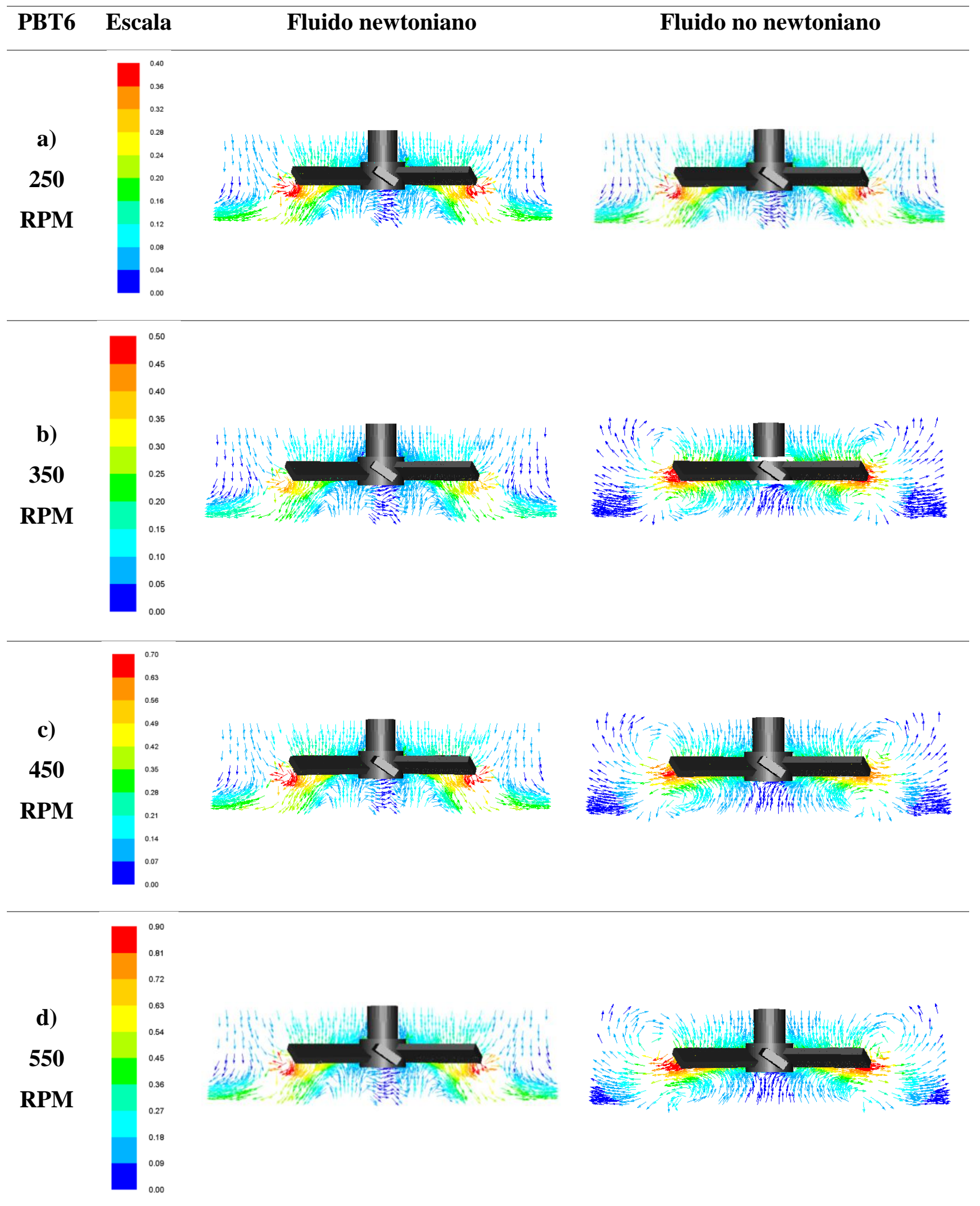

Figura 5.7. Vectores de velocidad de los fluidos newtoniano y no newtoniano a las velocidades a) 250, b) 350, c) 450 d) 550 RPM para el impulsor PBT6. 


\section{HE3 Escala}
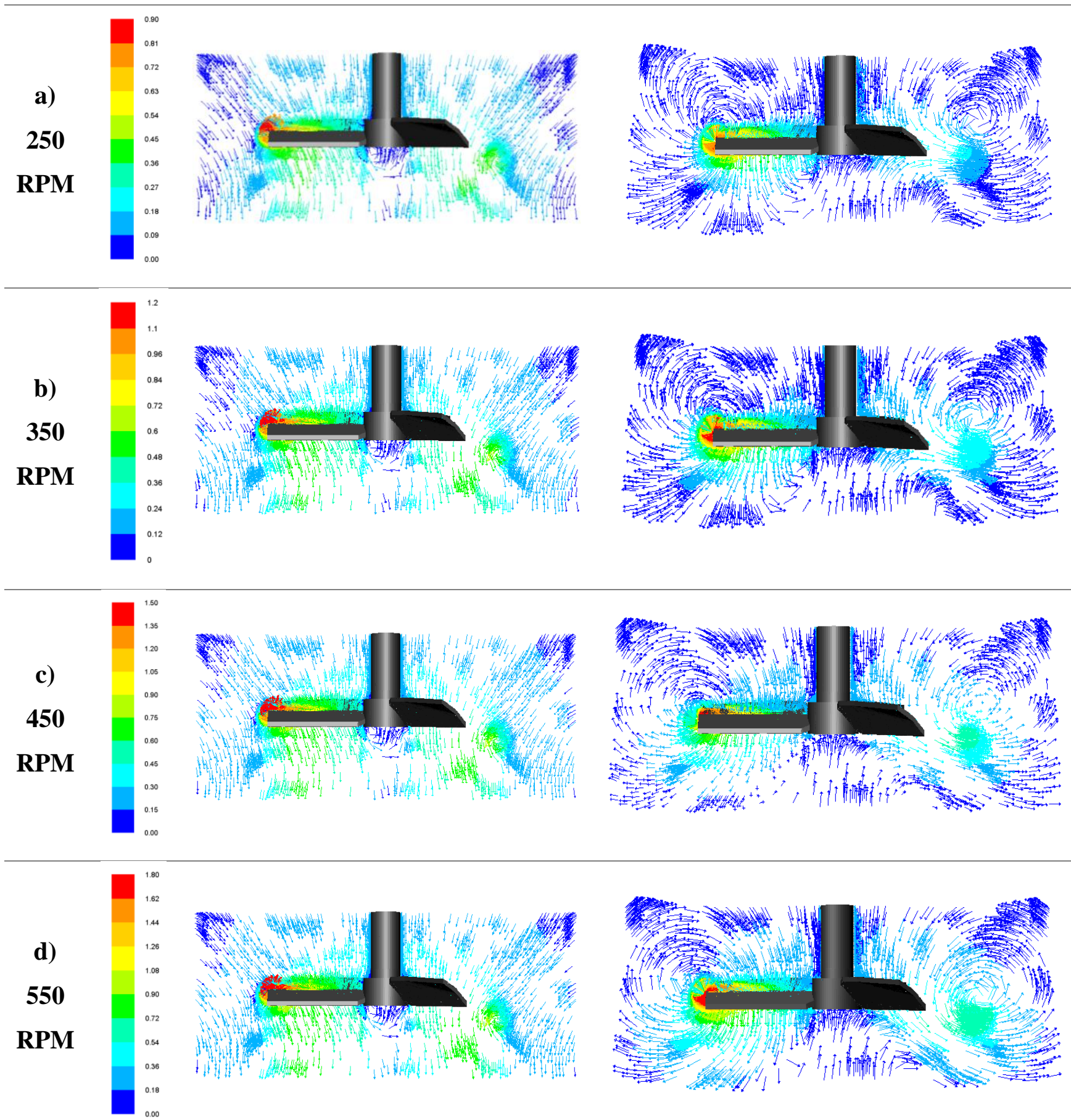

Figura 5.8. Vectores de velocidad de los fluidos newtoniano y no newtoniano a las velocidades a) 250, b) 350, c) 450 d) 550 RPM para el impulsor HE3. 


\subsection{Contornos de tasa de corte}

Las Figuras 5.9, 5.10 y 5.11 muestran los contornos de tasa de corte para el fluido newtoniano y no newtoniano en donde los colores indican la magnitud de la tasa de corte en esa superficie. Estas figuras fueron obtenidas en un plano de corte vertical que pasa a la mitad de por lo menos una de las paletas alineado con dos deflectores a cuatro diferentes velocidades (250, 350, 450 y 550 RPM) para cada uno de los impulsores: PBT4 (Figura 5.9), PBT6 (Figura 5.10) y HE3 (Figura 5.11).

Las escalas de colores no son las mismas para todas las imágenes presentadas debido a que la magnitud de la tasa de corte que se presentan en cada impulsor es diferente. Estos valores son afectados por las revoluciones de giro del impulsor y cada uno de los impulsores genera más o menos tasa de corte debido a la geometría de cada uno.

La tasa de corte más grande para cada velocidad de giro tanto para el fluido newtoniano como el no newtoniano se genera en la punta del impulsor y se va distribuyendo de manera axial y radial desde este punto.

Se observa que para el fluido newtoniano se genera una mayor tasa de corte en la componente axial por debajo del impulsor. Esto no sucede en el fluido no newtoniano ya que no se dispersa de la misma manera. Adicionalmente se observa con mayor claridad en el fluido newtoniano para los impulsores PBT4 y HE3 esta tasa de corte se distribuye completamente hacia abajo del impulsor y se nota en color verde mientras que en el impulsor PBT6 se desvía ligeramente hacia la componente radial, esto debido a la incidencia del fondo del tanque en el flujo del fluido. 


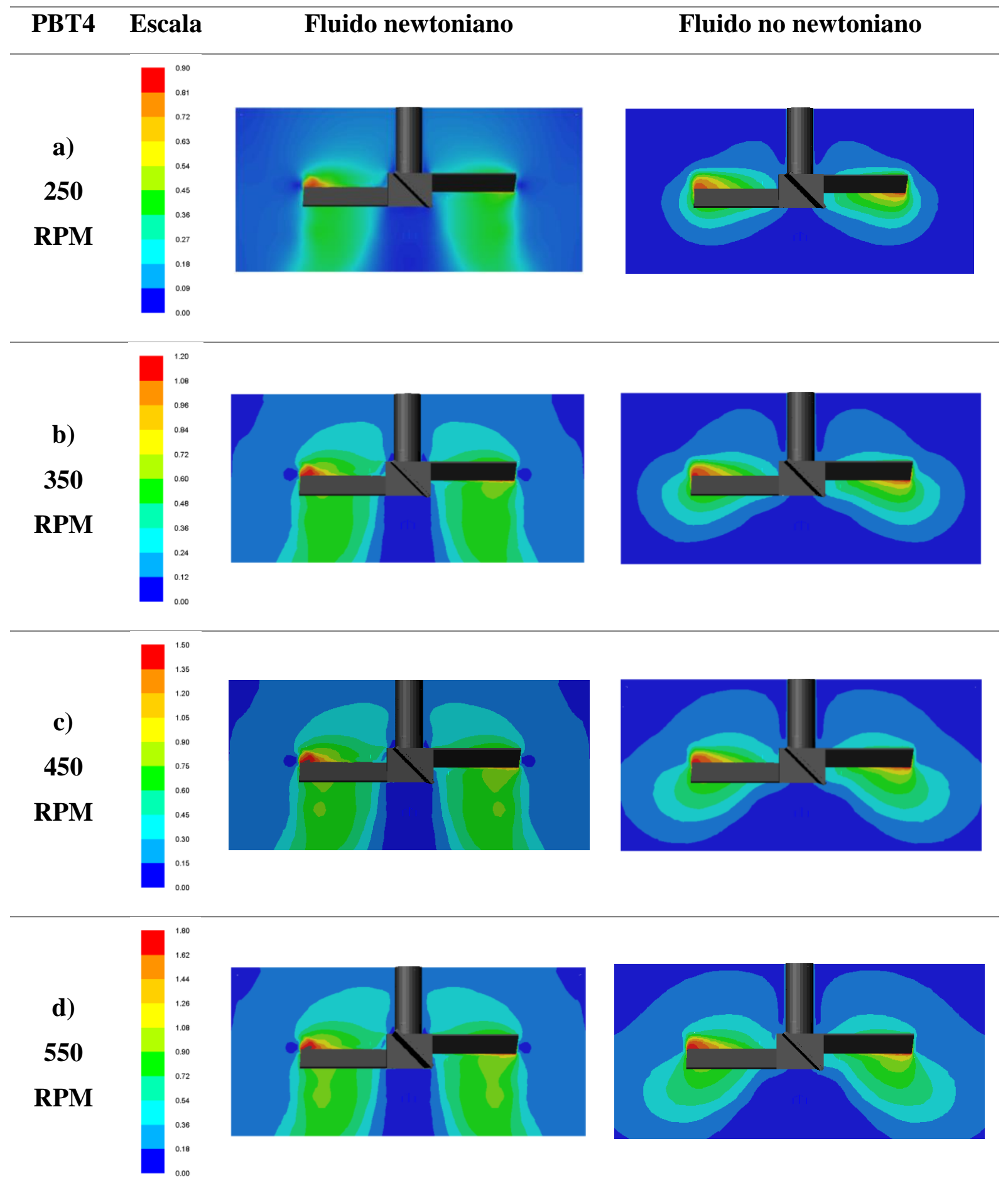

Figura 5.9. Contornos de tasa de corte de los fluidos newtoniano y no newtoniano a las velocidades a) 250, b) 350, c) 450 d) 550 RPM para el impulsor PBT4. 


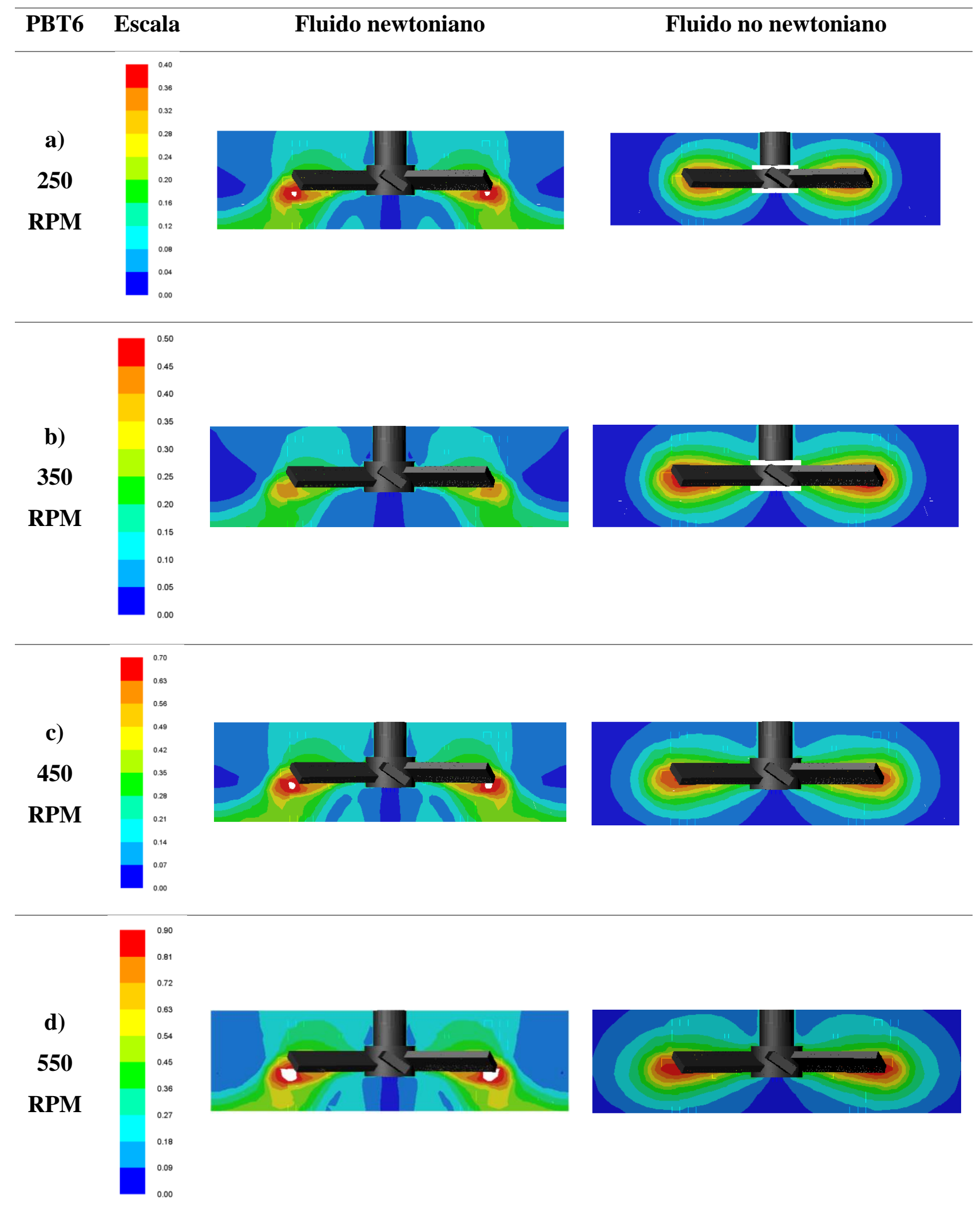

Figura 5.10. Contornos de tasa de corte de los fluidos newtoniano y no newtoniano a las velocidades a) 250, b) 350, c) 450 d) 550 RPM para el impulsor PBT6. 


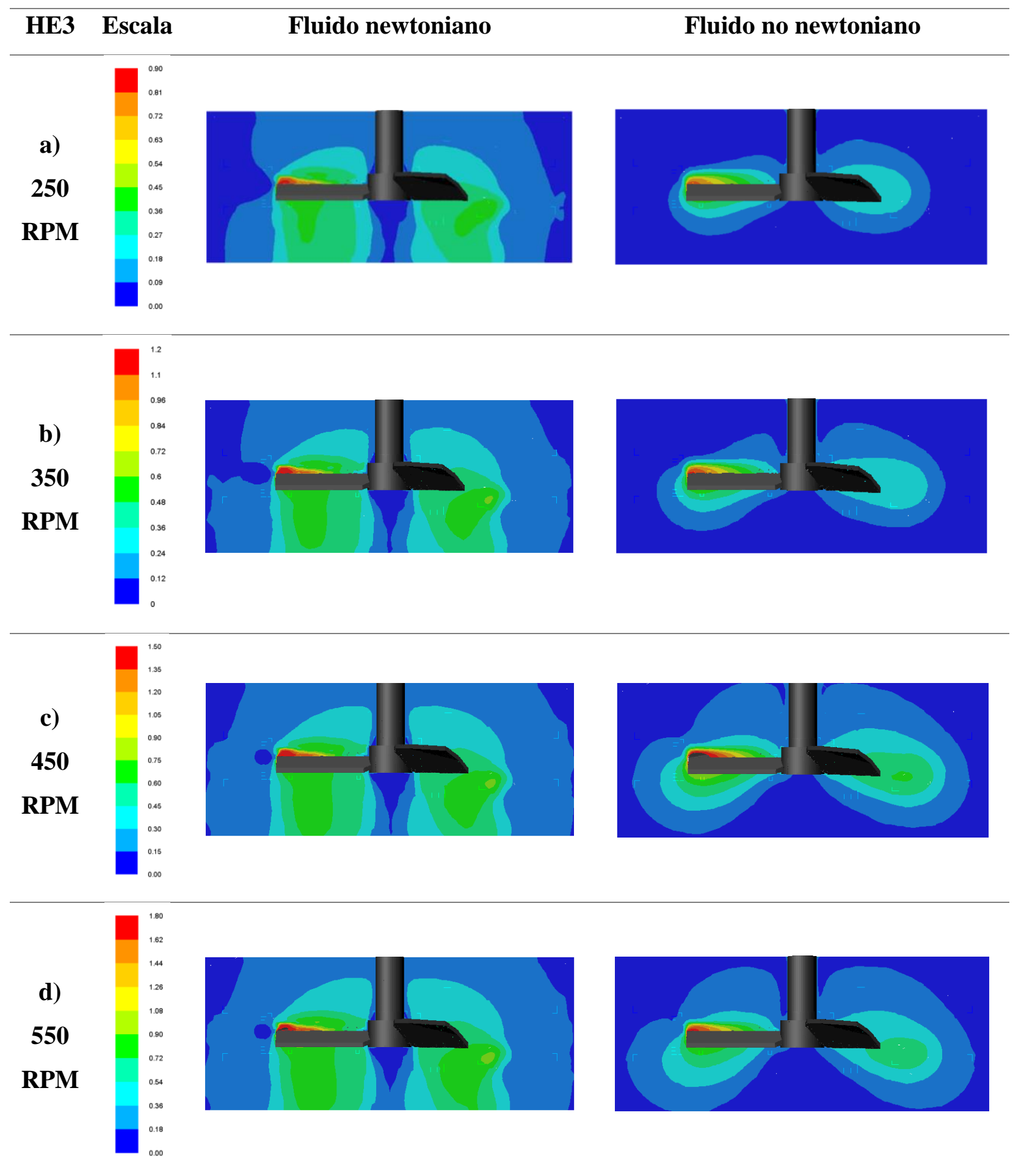

Figura 5.11. Contornos de tasa de corte de los fluidos newtoniano y no newtoniano a las velocidades a) 250, b) 350, c) 450 d) 550 RPM para el impulsor HE3. 


\subsection{Curvas de bombeo}

En la Figura 5.12 se muestran las curvas de bombeo de los tres impulsores analizados empleando el fluido newtoniano, se puede distinguir que el $\mathrm{N}_{\mathrm{Q}}$ es prácticamente contante en el régimen turbulento para los 3 impulsores. El impulsor que presenta el valor más alto de $\mathrm{N}_{\mathrm{Q}}$ es el PBT4 y el más bajo el PBT6.

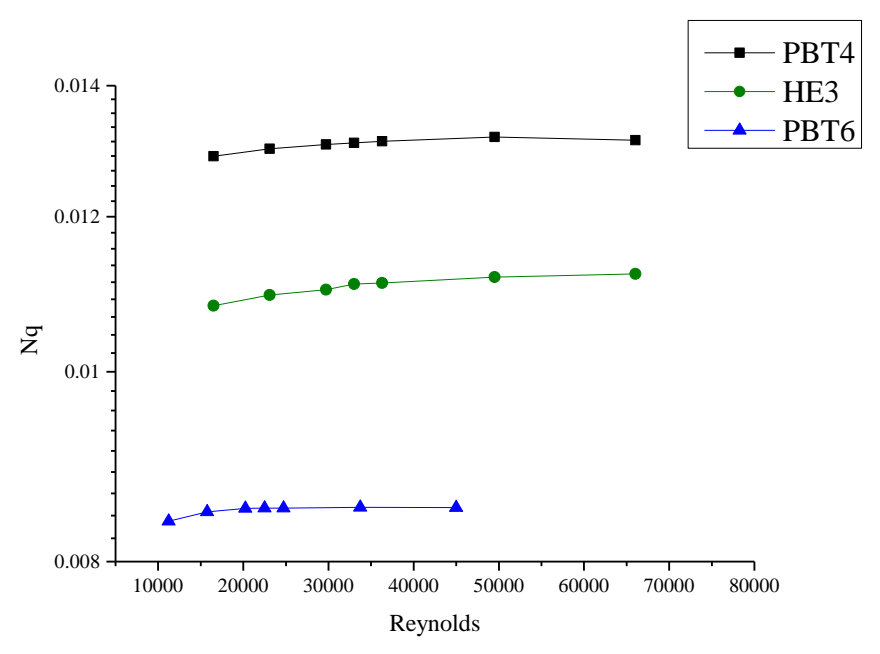

Figura 5.12. Relación de numero de bombeo vs Re para los impulsores PBT4, PBT6 y HE3 del fluido newtoniano.

Por otro lado, en la Figura 5.13 se muestran los resultados de bombeo a diferentes velocidades para el fluido no newtoniano. El impulsor que tiene un mayor bombeo es el PBT4 y el de menor es el PBT6. El comportamiento del bombeo del impulsor PBT6 tiene un comportamiento lineal, mientras que para el impulsor PBT4 y HE3 no lo es. En todos los casos, el bombeo incrementa al aumentar la velocidad de agitación. 


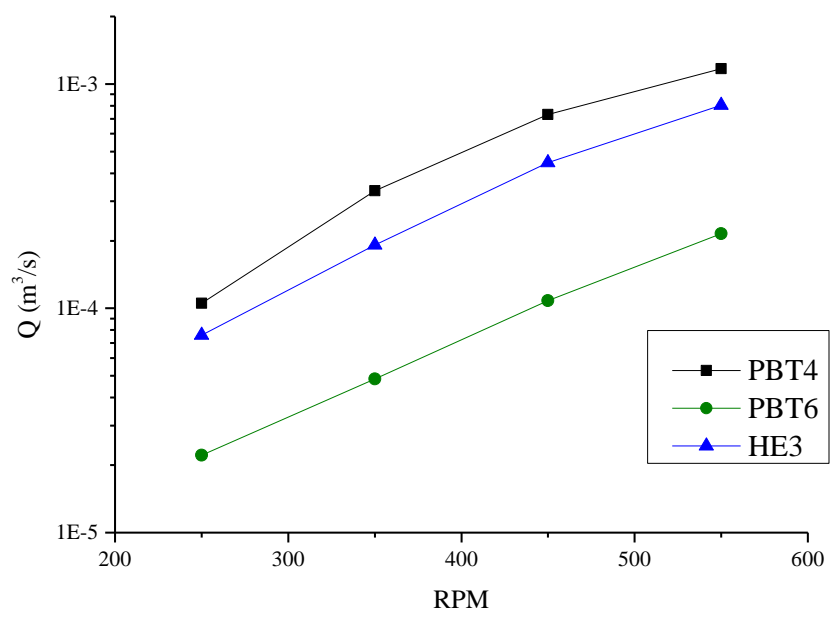

Figura 5.13. Bombeo por impulsor a diferentes velocidades para el fluido no newtoniano de los impulsores PBT4, PBT6 y HE3.

\subsection{Efectividad del mezclado}

La efectividad de mezclado se puede definir como el cociente entre el número de bombeo $\left(\mathrm{N}_{\mathrm{Q}}\right)$ y el número de potencia $\left(\mathrm{N}_{\mathrm{P}}\right)$ (Nienow, 1996). Su interpretación física es el caudal entregado por unidad de potencia consumida, por lo cual, valores grandes de $\mathrm{N}_{\mathrm{Q}} / \mathrm{N}_{\mathrm{P}}$ sugieren que una mayor cantidad de bombeo es producida por unidad de potencia suministrada. Además, como es el resultado del cociente de dos números adimensionales, y por tanto adimensional, se puede utilizar para comparar diferente tipo de agitadores. Cuanto mayor sea este parámetro mucho mejor porque significa que el agitador está expulsando gran cantidad de fluido sin consumir demasiada potencia (Martínez-López, 2006).

En la Figura 5.14 se muestra la efectividad de mezclado para el fluido newtoniano vs el número de Reynolds para los 3 impulsores en donde se observa que el que tiene mejor efectividad de mezclado es el HE3 y el menor es el PBT6. 


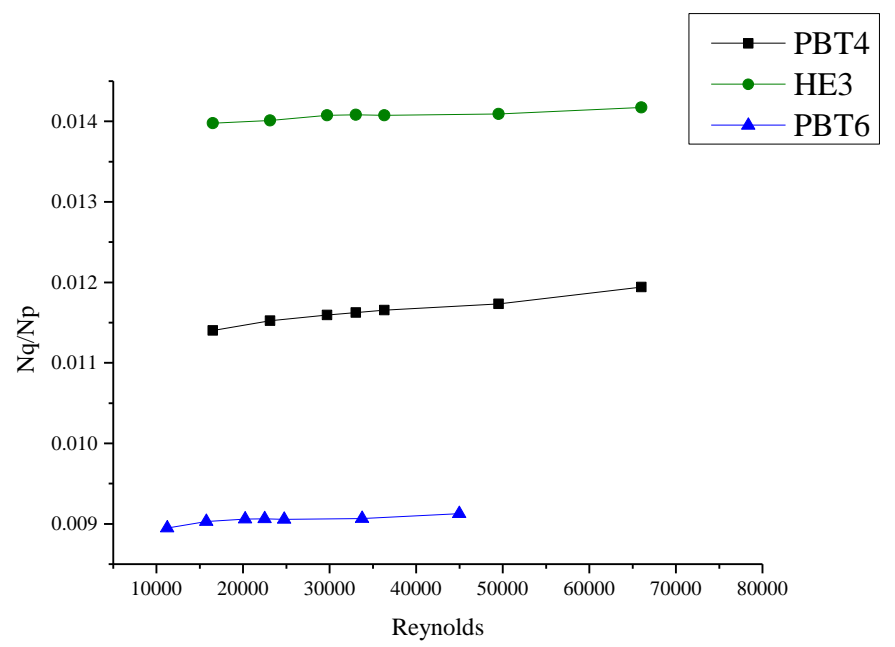

Figura 5.14. Relación de efectividad de mezclado vs Re para el fluido newtoniano de los impulsores PBT4, PBT6 y HE3.

En la Figura 5.15 se muestra la efectividad de mezclado para el fluido no newtoniano vs la velocidad para los 3 impulsores en donde se observa que los impulsores PBT4 y HE3 tienen casi la misma efectividad de mezclado y el PBT6 tiene menor comparado con los dos anteriores.

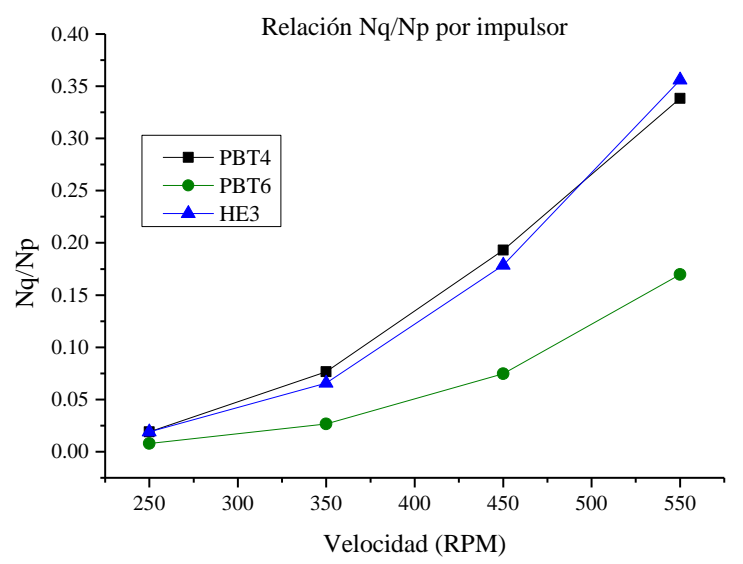

Figura 5.15. Relación de efectividad de mezclado $\left(\mathrm{N}_{\mathrm{Q}} / \mathrm{N}_{\mathrm{P}}\right)$ vs velocidad para el fluido no newtoniano de los impulsores PBT4, PBT6 y HE3. 


\section{CONCLUSIONES}

En el presente trabajo se caracterizó la hidrodinámica inducida por tres impulsores diferentes: PBT4, PBT6 y HE3 en el régimen de flujo turbulento con un fluido newtoniano (agua) y un recubrimiento blanco del sector automotriz como fluido no newtoniano adelgazante $\left(m=6.3929 \mathrm{~Pa} \cdot \mathrm{s}^{\mathrm{n}}\right.$ y $\left.n=0.3704\right)$. La caracterización se realizó mediante simulaciones CFD y los resultados fueron validados con mediciones experimentales de potencia. Se describieron los patrones de flujo y los vectores velocidad inducidos por el impulsor, su capacidad de bombeo, así como los perfiles locales y promedio de tasa de corte en regiones cercanas al impulsor.

Se encontró que la reología del fluido tiene un impacto mínimo en el patrón de flujo ya que tanto el fluido newtoniano como el no newtoniano formaron un solo lazo de circulación con una componente axial de velocidad que en el fluido no newtoniano es menor. Este campo de flujo es típico de los impulsores de flujo axial.

En cuanto a la dirección de la descarga del fluido inducido por el impulsor, se encontró que la componente axial se incrementa para el caso del fluido newtoniano. Los resultados obtenidos sugieren que para el caso específico de interés de este trabajo que es el mezclado de un recubrimiento blanco y un fluido newtoniano, el impulsor que exhibe un mejor desempeño es el PBT4 ya que es el que tiene la componente de la velocidad axial más grande.

De las curvas de bombeo se encontró que tanto para el fluido newtoniano como en no newtoniano el PBT4 es el que mantiene un bombeo total superior a los otros dos impulsores. Respecto a la efectividad de mezclado que se obtuvo de la relación $\mathrm{N}_{\mathrm{Q}} / \mathrm{N}_{\mathrm{P}}$ se encontró que el impulsor con la mayor efectividad en el fluido newtoniano es el HE3 mientras que para el fluido no newtoniano los impulsores PBT4 y HE3 presentan casi el mismo desempeño.

La metodología seguida en este trabajo puede ser utilizada para la caracterización del consumo de potencia y bombeo en otros sistemas de mezclado con impulsores que tengan un número diferente de paletas o diferentes ángulos de ataque, ya sea en escala laboratorio planta. 
Una vez obtenidas las conclusiones anteriores se determinó que el mejor impulsor de las tres propuestas es el PBT4 ya que con los resultados mostrados en los diferentes parámetros muestra una versatilidad en cuanto a tipos de fluidos que se pueden homogeneizar en régimen turbulento manteniendo las ventajas que este mismo posee. Estas ventajas son útiles para la aplicación industrial definida en este proyecto, con el uso de este impulsor se asegura la completa homogeneización del material debido a los patrones de flujo encontrados en las diferentes velocidades de agitación y los valores de efectividad de mezclado.

La continuación que se propone para este trabajo es analizar los mismos impulsores en régimen laminar adicionando un disco dentado tipo Cowless basado en una aplicación industrial. Dentro de Axalta existen recubrimientos de viscosidades muy altas en las que se dificulta la homogeneización.

El estudio de este proyecto se puede continuar para llegar a realizar la validación en tamaño industrial con los siguientes pasos:

1. Análisis de impacto económico.

(1) Desarrollar de manera formal con área de Ingeniería de Proyectos.

(2) Calcular monto de inversión y TIR.

(3) Calcular reducción de tiempo de ciclo e incremento de la capacidad productiva.

2. Extracción de datos de tiempo de mezclado.

(1) Realizar mediciones de color en diferentes tiempos de mezclado para caracterizar el sistema actual.

3. Implementar el cambio en el diseño del sistema agitado.

(1) Realizar los cambios físicos necesarios en el tanque agitado.

4. Validar efectividad del cambio.

(1) Realizar mediciones de color en diferentes tiempos y compararlos con el sistema anterior. 


\section{REFERENCIAS}

AMAIA, (2018). Dialogo con la industria automotriz. AMAIA.

Anderson, J.D., Degrez, G., Dick, E., Grundmann, R., (2013). Computational fluid dynamics: an introduction. Springer Science \& Business Media.

Axalta Coating Systems, (2019). Nuestra Historia de Axalta Coating systems México. Axalta Coating Systems.

Beshay, K.R., Kratěna, J., Fořt, I., Brůha, O., (2001). Power Input of High-Speed Rotary Impellers. Czech Technical University Publishing House, Cairo, Egypt. edición ed. Limusa Wiley.

Bujalski, J.M., Jaworski, Z., Bujalski, W., Nienow, A.W., (2002). The influence of the addition position of a tracer on CFD simulated mixing times in a vessel agitated by a Rushton turbine. Chemical Engineering Research and Design 80(8), 824-831.

Crane, (1988). Flujo de Fluidos en válvulas, accesorios y tuberías. Mc Graw Hill. Chaverra, D., (2016). Cifras del sector de pinturas. IMPRA LATINA.

Cheng, D., Feng, X., Cheng, J., Yang, C., (2013). Numerical simulation of macromixing in liquid-liquid stirred tanks. Chemical Engineering Science 101(20), 272282.

De La Concha-Gómez, A., Ramírez-Muñoz, J., Márquez-Baños, V., Haro, C., AlonsoGómez, A., (2019). Effect of the Rotating Reference Frame size for simulating a mixing straight-blade impeller in a baffled stirred tank. Revista Mexicana de Ingeniería Química 18(3), 1143-1160.

Derksen, J.J., Doelman, M.S., Van den Akker, H.E.A., (1999). Three-dimensional LDA measurements in the impeller region of a turbulently stirred tank. Experiments in Fluids 27(6), 522-532.

Deglon, D.A., Meyer, C.J., (2006). CFD modelling of stirred tanks: Numerical considerations. Minerals Engineering 19(10), 1059-1068.

Fluent, A., (2018). 17.1 Theory Guide. Ansys Inc.

García-Cortés, D., Jáuregui-Haza, U., (2006). Hidrodinámica en tanques agitados con turbinas de disco con paletas planas. Revista Facultad de Ingeniería Universidad de Antioquia 38, 97-113. 
Grenville, R.K., Giacomelli, J.J., (2017). Mixing: Impeller Performance in Stirred Tanks. Chemical Engineering Mcgraw Hill, USA.

Holland, F.A., Chapman, F.S., (1966). Liquid mixing and processing in stirred tanks. Reinhold Pub. Corp.

Holland, F.A.C., F. S., (1966). Liquid mixing and processing in stirred tanks. Reinhold Pub. Corp.

Jaworski, Z., Dudczak, J., (1998). CFD modelling of turbulent macromixing in stirred tanks. Computers \& chemical engineering 20, S293-S298.

Joshi, J.B., Nere, N.K., Rane, C.V., Murthy, B.N., Mathpati, C.S., Patwardhan, A.W., Ranade, V.V., (2011). CFD simulation of stirred tanks: comparison of turbulence models. Part I: Radial flow impellers. Can. J. Chem. Eng. 89, 23-82.

Kamla, Y., Bouzit, M., Ameur, H., Arab, M.I., Hadjeb, A., (2017). Effect of the Inclination of Baffles on the Power Consumption and Fluid Flows in a Vessel Stirred by a Rushton Turbine. Chinese Journal of Mechanical Engineering 30, 1008-1016.

Márquez-Baños, V.E., De La Concha-Gómez, A.D., Valencia-López, J.J., LópezYáñez, A., Ramírez-Muñoz, J., (2019). Shear rate and direct numerical calculation of the Metzner-Otto constant for a pitched blade turbine. ELSEVIER.

Marrion, A., (2004). The Chemistry and Physics of Coatings. The Royal Society of Chemistry, United Kingdom.

Martínez-de Jesús, G., Ramírez-Muñoz, J., García-Cortés, D., Cota, L.G., (2018). Computational Fluid Dynamics Studyof Flow Induced by a Grooved HighShearImpeller in an Unbaffled Tank. Chemical Engineering \& Technology 40(3), 580-589.

Martínez-López, D., (2006). Simulación de una turbina radial mediante CFD FLUENT: caso de una turbina Rushton. Universidad Politécnica de Cataluña.

Mott, R.L., (1996). Mecánica de fluidos aplicada. Pearson Educación.

Murthy, J.Y., Mathur, S.R., Choudhury, C., (1994). CFD simulation of flow in stirred tanks reactor using a sliding mesh technique. . Eighth European Conference on Mixing 136, 341-345.

Nienow, A.W., (1996). On impeller circulation and mixing effectiveness in the turbulent flow regime. Chemical Engineering Science. 
Oldshue, J.Y., (1983). Fluid Mixing Technology and Practice. McGraw-Hill, New York.

Oshinowo, L., Bakker, A., Marshall, E., (1999). Mixing Time-A CFD Approach, 17th Biennial North American Mixing Conference Banff, Alberta.

Oshinowo, L., Jaworski, Z., Dyster, K.N., Marshall, E., Nienow, A.W., (2000). Predicting the tangential velocity field in stirred tanks using the Multiple Reference Frames (MRF) model with validation by LDA measurements, 10th European conference on mixing. Elsevier, pp. 281-288.

Paul, E.L., Atiemo-Obeng, V.A., Kresta, S.M., (2004). Handbook of Industrial Mixing: Science and Practice.

Ramírez-Gómez, R., García-Cortés, D., Martínez-de Jesús, G., González-Brambila, M.M., Alonso, A., Martínez-Delgadillo, S.A., Ramírez-Muñoz, J., (2015). Performance Evaluation of Two High-ShearImpellers in an Unbaffled Stirred Tank. Chemical Engineering \& Technology 38(9), 1519-1529.

Ramírez-Muñoz, J., Guadarrama-Pérez, R., Márquez-Baños, V.E., (2017). A direct calculation method of the Metzner-Otto constant by using computational fluid dynamics. Chemical Engineering Science.

Wendt, J.F., (2008). Computational fluid dynamics: an introduction. Springer Science \& Business Media.

Zlokarnik, M., (2006). Scale-Up in Chemical Engineering. WILEY-VCH Verlag $\mathrm{GmbH} \& \mathrm{Co} . \mathrm{KGaA}$, Austria. 